\title{
Arquitetura deposicional e evolução da seqüência aluvial neocretácea da porção setentrional da Bacia Bauru, no sudeste brasileiro
}

\author{
Alessandro Batezelli', Antonio Roberto Saad ${ }^{2}$ \& Giorgio Basilici ${ }^{3}$
}

\begin{abstract}
Resumo A reconstrução de macroformas através da análise de fácies e análise de elementos arquitetônicos tem sido bastante utilizada para definição de geometria dos depósitos fluviais, e conseqüentemente, da evolução da arquitetura aluvial. Através de informações advindas de seções bidimensionais de afloramentos do Grupo Bauru na região oeste de Minas Gerais (Triângulo Mineiro), nordeste do Mato Grosso do Sul e Sul de Goiás, foram elaborados modelos que ilustram as geometrias dos litossomas que constituem a seqüência neocretácea. As características faciológicas associadas às macroformas de acréscimo a jusante (elemento DA), formas de leito arenoso (elemento SB), barras cascalhentas e canais (elementos SG e CH), indicam que o ambiente deposicional era formado por rios do tipo entrelaçado de baixa sinuosidade, associados a um sistema de leques aluviais. Dados de paleocorrentes indicam que a área fonte desses depósitos se localizava principalmente na porção nordeste e norte da Bacia Bauru, nas estruturas conhecidas como Soerguimento do Alto Paranaíba e Província Alcalina de Goiás, resultante de intrusões alcalinas durante o Cretáceo Superior. As características deposicionais permitiram a reconstrução da arquitetura aluvial da porção centro-norte da bacia, fornecendo informações sobre as variações do nível de base, taxa de sedimentação e espaço de acomodação de sedimentos. Utilizando uma terminologia alternativa para depósitos continentais, o modelo de evolução da seqüência aluvial neocretácea da Bacia Bauru contempla um trato de sistema de alta taxa de acomodação em sua porção basal (formações Araçatuba e Adamantina), e o trato de sistema de baixa taxa de acomodação na porção superior (formações Uberaba e Marília).
\end{abstract}

Palavras-chave: Bacia Bauru, elementos arquitetônicos, reconstrução de macroformas, arquitetura aluvial, tratos de sistemas de baixa e alta acomodação.

\begin{abstract}
Depositional architecture and neocretaceous alluvial sequence evolution of northern Bauru Basin, in the southeast Brazil The macroforms reconstructions using facies and architectural element analysis has been an important stratigraphic tool to delimit fluvial deposits geometries, and alluvial architecture evolution. Outcrops information of the Bauru Group from western Minas Gerais State (Triângulo Mineiro), northeastern of Mato Grosso do Sul, and southern Goiás, allowed to elaborate models that shows the litossom geometries of the neo-cretaceous sequence. The faciological characteristics associated to downstream macroforms (DA Element), Sandy bars (SB Element), gravel bars and channels (GB and CH Elements) are indicating the paleoenvironment as low-sinuosity braided river dominated, associated to alluvial fan system. Paleocurrent data indicate that source area were mainly in the north and northeast of the Bauru Basin, in the Alto Paranaíba Uplift and Alkaline Complex of South Goiás. The depositional characteristic has permitted to reconstruct the northern basin alluvial architecture, given important information about base level changes, sedimentation rate and accommodation space. Applying an alternative terminology to continental stratigraphic sequence, the evolution model of the neo-cretaceous alluvial sequence shows the high accommodation system tract to its lowest units (Araçatuba and Adamantina Formations), and low accommodation system tract to uppers (Uberaba and Marília formations).
\end{abstract}

Keywords: Bauru Basin, architectural elements, macroforms reconstruction, alluvial architecture, low- and high accommodation system tracts.

INTRODUÇÃO A Bacia Bauru, entidade geotectônica gerada no Cretáceo Superior na porção sudeste da Placa Sul-americana, sobreposta à região centro-norte da antiga Bacia do Paraná, possui uma área de 330.000 $\mathrm{km}^{2}$ no território brasileiro, e teve sua gênese relacionada à reativação de antigas estruturas do embasamento (lineamentos de Três Lagoas, Presidente Prudente e Ri- beirão Preto - Hasui et al., 1989) (Fig. 1).

Seu substrato é formado em parte por arenitos do Grupo Caiuá (Cretáceo Inferior), e por basaltos da Formação Serra Geral (Grupo São Bento - Cretáceo Inferior), rearranjados sob a forma de uma depressão alongada na direção NE-SW, por influência de esforços direcionais intraplaca ocasionados pela separação Bra-

1 - IGe, DGRN, UNICAMP, Campinas, SP. E-mail: batezelli@ige.unicamp.br ou alessandro.batezelli@gmail.com

2 - IGCE, UNESP, Rio Claro, S.P. E-mail: dga@rc.unesp.br e Universidade Guarulhos, Guarulhos, S.P. E-mail: asaad@prof.ung.br

3 - IGe, DGRN, UNICAMP, Campinas, SP 
sil-África a leste. Embora o arranjo tridimensional das rochas que compõem a Bacia Bauru constitua matéria amplamente discutida na bibliografia geocientífica desde o início do século 20 , o presente trabalho não aborda uma discussão aprofundada sobre sua estratigrafia formal. Seguindo a concepção estratigráfica de Batezelli (2003) e Batezelli et al. (2003), essa bacia registra sedimentação continental constituída por rochas lamíticas e arenitos muito finos na base (formações Araçatuba e Adamantina), gradando para arenitos finos a médios na sua porção intermediária (formações Adamantina e Uberaba), e arenitos médios/grossos, ora conglomeráticos, no topo (Formação Marília) (Fig. 2).

Sendo suas rochas caracterizadas predominantemente pela gênese em ambiente de leques aluviais re- trabalhados por rios entrelaçados (Batezelli, 2003; Batezelli et al. 2003), esse trabalho apresenta uma análise sedimentológica/estratigráfica de afloramentos buscando reconstruir a arquitetura deposicional e variações nos estilos fluviais ao longo da evolução da bacia.

Entre os métodos aplicados destaca-se a análise de fácies e elementos arquitetônicos de afloramentos conforme proposta de Miall (1985), permitindo assim, a construção de modelos tridimensionais que facilitam a visualização dos litossomas.

Por fim, é apresentada uma proposta de evolução para a seqüência estratigráfica neocretácea na porção norte e nordeste da Bacia Bauru, baseada nos conceitos de Martinsen et al (1999), fundamentada nas variações da arquitetura deposicional em função das-

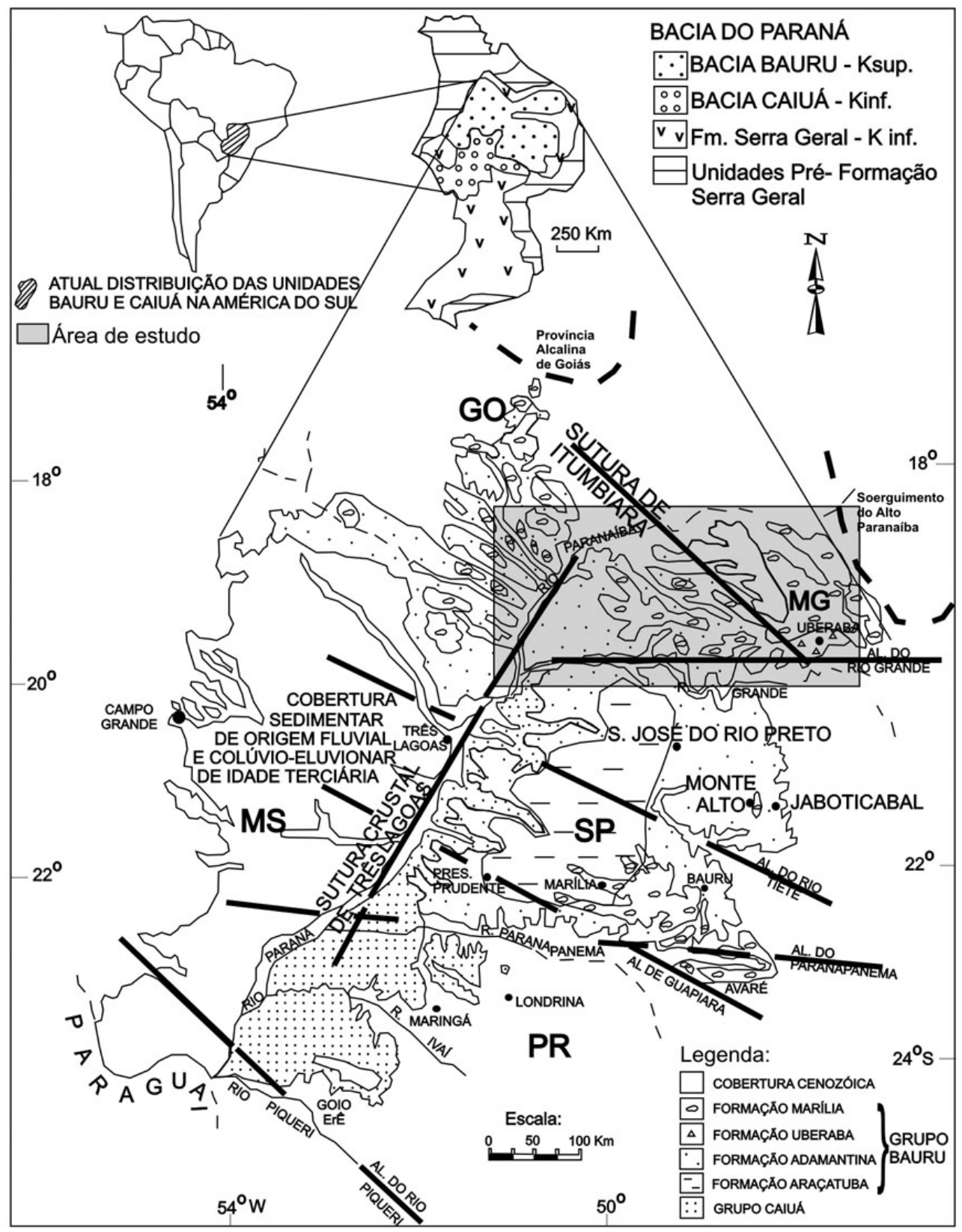

Figura 1 - Localização da Bacia Bauru e distribuição das unidades litoestratigráfcas (Fernandes \& Coimbra, 2000 - mod.). 


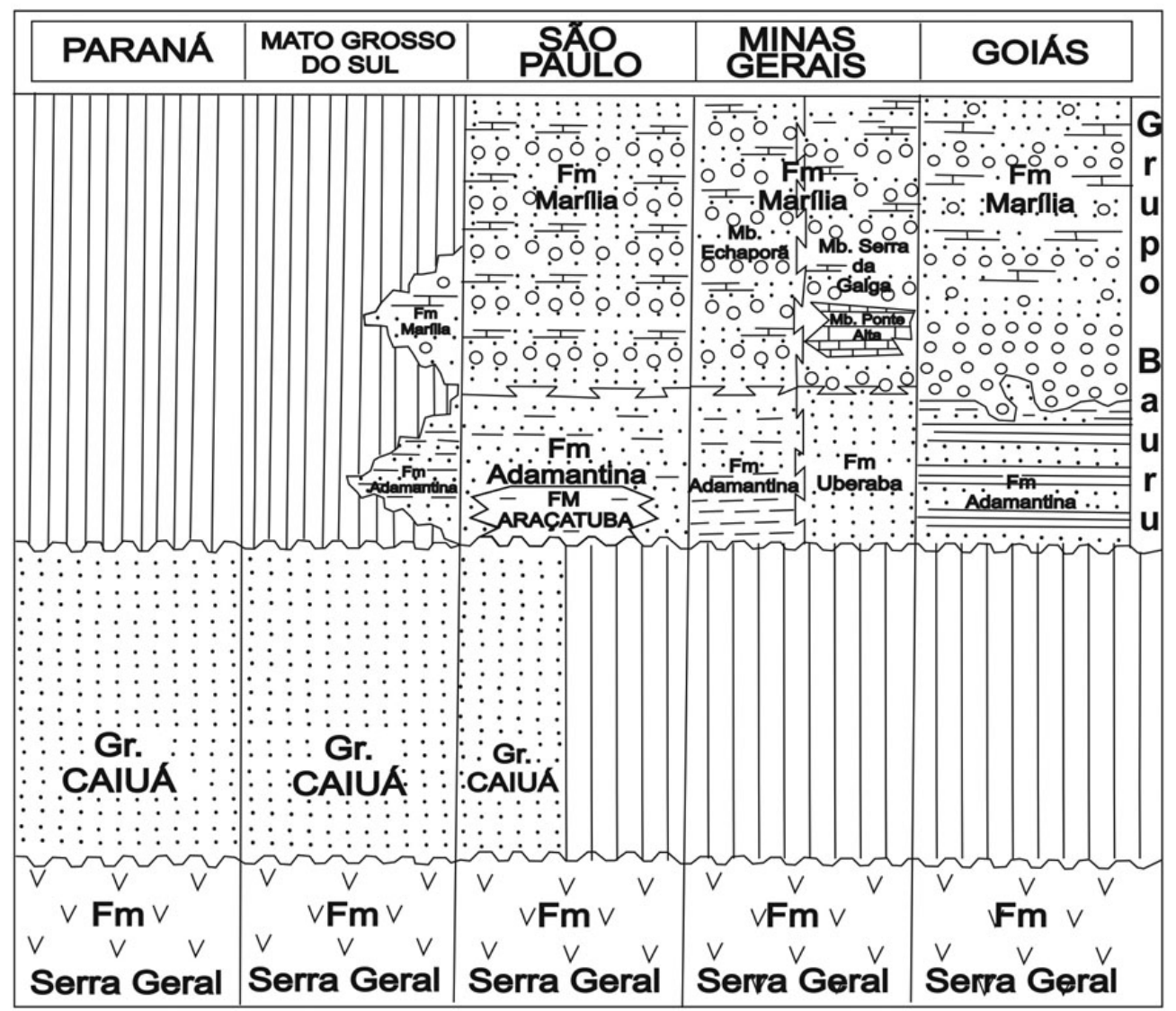

Figura 2 - Coluna litoestratigráfica da Bacia Bauru nas diferentes áreas de ocorrências (Batezelli, 2003).

mudanças no nível de base estratigráfico e taxa de acomodação. Dessa forma, estão sendo propostos dois tratos de sistemas para a Bacia Bauru: trato de sistema de alta taxa de acomodação (high-accommodation system tract) e trato de sistema de baixa de acomodação (low accommodation system tract).

\section{ÁREA DE ESTUDO, MATERIAIS E MÉTODOS} DE TRABALHO Para elaboração desse trabalho foram realizadas coletas de dados de campo em uma área aproximada de $70.000 \mathrm{~km}^{2}$ na porção norte e nordeste da Bacia Bauru, na região conhecida com Triângulo Mineiro (MG), bem como em áreas adjacentes no estado de São Paulo, nordeste do Mato Grosso do Sul e sul de Goiás (Fig. 1). Foram identificadas fácies e associações de fácies, geometrias internas e natureza dos contatos nos litossomas, relação vertical dentre as fácies, e medidas de indicadores de paleocorrentes (orientação de foresets de estratificações cruzadas).

O método de análise de fácies foi baseado em Miall (1978), em que é atribuída a cada uma das fácies identificadas, um código no qual a rocha é indicada por uma letra maiúscula $(\mathrm{C}=$ conglomerado, $\mathrm{A}=$ Arenito), seguida por uma letra minúscula indicativa de uma característica marcante da fácies. Quando necessário, adicionou-se uma terceira ou quarta letra para indicar atributos que a diferenciem das demais fácies (Tab. 1).

A fim de se obter uma visão tridimensional dos depósitos sedimentares da Bacia Bauru, foi utilizada a análise de elementos arquitetônicos proposta originalmente por Miall (1985) e utilizada por muitos autores para determinação de estilos fluviais (e.g. Miall 1988a, 1988b, 1994 e 1996; Miall \& Turner-Peterson, 1989; Miall \& Tyler, 1991; Smith, 1990; Cowan, 1991; Decelles et al, 1991; Bridge, 1993; Ferreira Jr. \& Guerra, 1995; Ferreira Jr., 1996; Lima \& Villas-Boas, 2000; Jones et al., 2001; Batezelli, 2003; Miall \& Jones, 2003; Komatsubara, 2004, entre outros). A utilização desse método deveu-se, sobretudo, aos vários afloramentos com grande extensão lateral que ocorrem na área estudo, permitindo assim a confecção de painéis fotográficos para análise do traçado das superfícies limítrofes dos litossomas, identificação de superfícies hierárquicas e de macroformas.

Durante os trabalhos de campo, foram medidas atitudes de indicadores de paleocorrente, principalmente estratificações cruzadas. Essas medidas foram tratadas estatisticamente por meio do software Rockworks da Rockwere gerando diagramas em rosetas. Os vetores médios dos diagramas foram indicados na base cartográfica da área gerando um mapa de paleocorrentes.

ELEMENTOS ARQUITETÔNICOS, MACROFORMAS E SUPERFÍCIES HIERÁRQUICAS DA PORÇÃO NORTE E NORDESTE DA BACIA BAURU Para a análise dos elementos arquitetônicos 
Tabela 1 - Código de fácies utilizado no estudo do Grupo Bauru no Triângulo Mineiro e áreas adjacentes.

\begin{tabular}{c|c|l}
\hline $\begin{array}{c}\text { Conjunto de } \\
\text { Fácies }\end{array}$ & Fácies & \multicolumn{1}{c}{ Características } \\
\hline \multirow{4}{*}{ C } & Cmm & Conglomerado maciço, sustentado por matriz. \\
\cline { 2 - 3 } & Cmg & Conglomerado maciço, sustentado por clastos. \\
\cline { 2 - 3 } & Ceag & Conglomerado com estratificação cruzada acanalada, sustentado por clastos. \\
\cline { 2 - 3 } & Ceam & Conglomerado com estratificação cruzada acanalada, sustentado por matriz. \\
\hline \multirow{4}{*}{ A } & Am & Conglomerado com estratificação cruzada tabular, sustentado por clastos. \\
\cline { 2 - 3 } & Aea & $\begin{array}{l}\text { Arenito maciço, com ou sem clastos dispersos. } \\
\text { grande porte Aeag). }\end{array}$ \\
\cline { 2 - 4 } & Aeab & Arenito com estratificação cruzada acanalada de baixo ângulo. \\
\cline { 2 - 3 } & Aet & Arenito com estratificação cruzada tabular (pequeno, médio e grande porte). \\
\cline { 2 - 3 } & Aeh & Arenito com estratificação sub-horizontal. \\
\cline { 2 - 3 } & Alp & Arenito com laminação plano-paralela. \\
\cline { 2 - 3 } & Ao & Arenito com marcas onduladas. \\
\cline { 2 - 3 } & Ar & Arenito granodecrescente ascendente. \\
\hline
\end{tabular}

e macroformas da Bacia Bauru foram delimitadas superfícies hierárquicas nos fotomosaicos de afloramentos ao longo da faixa aflorante na região do Triângulo Mineiro, norte de São Paulo, nordeste do Mato Grosso do Sul e Sul do Goiás. O critério de escolha dos afloramentos estudados baseou-se principalmente nas dimensões das exposições. Já para a confecção do mapa de paleocorrentes foram usadas também informações adicionais de outros afloramentos da área de estudo.

Para a diferenciação entre as macroformas de acréscimo à jusante (Elemento DA) e macroformas de acréscimo lateral (Elemento LA), foi determinado o padrão de paleocorrente local em cada seção. Com base da determinação da direção de paleocorrentes foi possível identificar e diferenciar essas macroformas de acordo com os critérios utilizados por Miall (1994) e Jones et al., (2001). Dessa forma, quando o rumo da inclinação das superfícies que definem as macroformas tende a fazer um ângulo maior que 60 graus com a orientação das estratificações cruzadas locais (superfícies de $1^{\mathrm{a}} \mathrm{e} 2^{\mathrm{a}}$ ordem) elas são macroformas de acréscimo lateral (LA). Quando o rumo de inclinação das macroformas faz um ângulo menor que 60 graus com a orientação das estratificações cruzadas (superfícies de $1^{\mathrm{a}}$ e $2^{\mathrm{a}}$ ordem), essas são interpretadas como macroformas de acréscimo à jusante (DA). Os elementos arquitetônicos identificados na área de estudo estão descritos de acordo com suas importâncias e maior ocorrência nos afloramentos, embora, algumas das seções apresentem vários elementos presentes.

Macroformas de acréscimo à jusante (DA) e formas de leitos arenosos (SB) As seções onde foram identificadas as macroformas de acréscimo à jusante loca- lizam-se, sobretudo nas imediações da cidade de Uberaba (Seções AB-03, AB-62) e Frutal (Seção AB-101b) no estado de Minas Gerais. Em ambas as localidades são possíveis observar semelhanças nas características faciológicas, bem como, nas geometrias internas e externas. Nessas seções também são identificados canais menores (elemento $\mathrm{CH}$ ).

SEÇÃO AB-03 A seção AB-03 (Fig. 3) está localizada em um corte na Avenida Doutor Rodolpho Borges Jr. (Via Verde), próximo ao Mirante, no perímetro urbano da cidade de Uberaba (MG). É constituída basicamente pelas fácies Aet, Aea, Aeh, e, subordinadamente Cea. Observa-se nessa seção um domínio de superfícies de $1^{\text {a }}$ ordem, representadas por estratificações cruzadas tabulares e acanaladas, e superfícies de $2^{\text {a }}$ ordem que limitam os estratos com até $70 \mathrm{~cm}$ de espessura. As superfícies de $3^{a}$ ordem possuem forma côncava para o topo, truncadas suavemente no topo por superfícies de $3^{\mathrm{a}}$ e $4^{\mathrm{a}}$ ordem, delimitando 3 macroformas de acréscimo à jusante (elementos 1-DA, 2-DA e 3-DA) com aproximadamente 1 metro de espessura e até 30 metros de comprimento. Internamente observam-se superfícies de $2^{\mathrm{a}}$ ordem (inclinadas ou horizontais) que limitam estratos arenosos com estratificações cruzadas tabulares e acanaladas (superfícies de $1^{a}$ ordem). Essas superfícies possuem direção média N 168 com inclinações da ordem de $20^{\circ}$. Na base das superfícies de $3^{a}$ ordem é comum encontrar a fácies Cea. Também é identificado um elemento 1-SB (formas de leito arenoso) no topo do afloramento.

SEÇÃO AB-62 Localizada na rodovia BR-050, a 300 metros do Rio Uberaba em direção à Uberlândia, ainda 


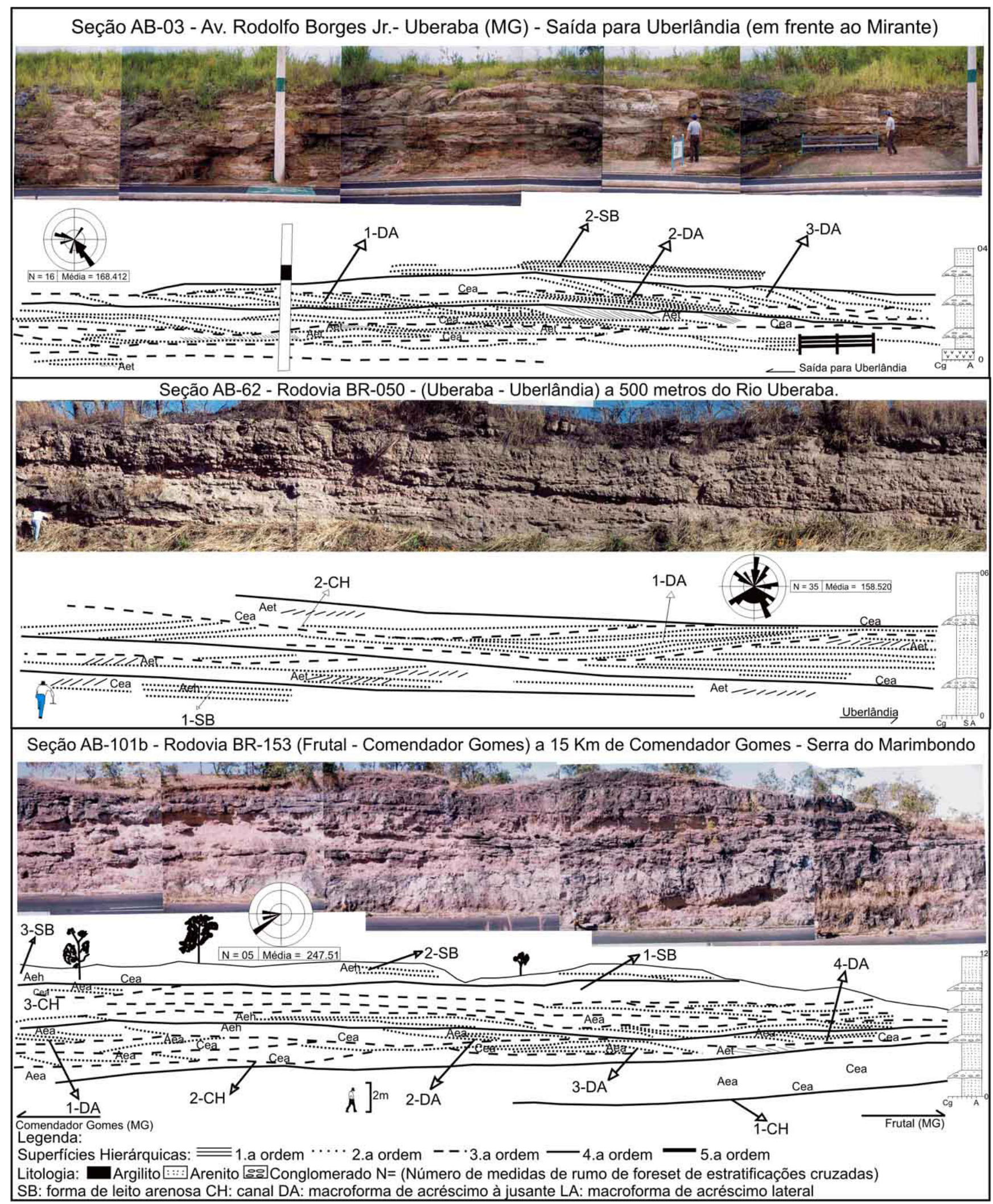

Figura 3 - Elementos arquitetônicos dos afloramentos AB-03, AB-62 e AB-101.

no perímetro urbano de Uberaba (MG), a seção $\mathrm{AB}-62$ (Fig. 3) possui uma extensão de 120 metros com altura aproximada de 10 metros. Suas características faciológicas são muito semelhantes às encontradas na seção AB-03, com predomínio das fácies Aet e Aea, e subordinadamente Cea e Alp.
Três superfícies de $4^{\text {a }}$ ordem delimitam o afloramento em 4 estratos, sendo o basal com 1,5 metros de espessura, onde se encontra, à esquerda, um pequeno canal (Elemento 1-CH - fácies Cea) e uma forma de leito arenosa (Elemento 1-SB) com geometria tabular e 1,5 metros de espessura caracterizada pela fácies Alp. 
$\mathrm{Na}$ porção média do afloramento, em contato brusco, aparece um estrato com 1 metro de espessura que encerra principalmente a fácies Aet. Ainda na porção média da seção destaca-se a presença marcante de uma macroforma de acréscimo à jusante (Elemento 1-DA) delimitada por 2 superfícies de $3^{\text {a }}$ na base e no topo descrevendo um formato sigmóide com 15 metros de comprimento e constituída pelas fácies Aea e Aet. Também nessa porção do afloramento aparece um canal com 30 metros de comprimento que trunca o elemento 1-DA à esquerda e é constituído pelas fácies Cea e Aea.

Na porção superior da seção é encontrada as fácies Alp, Aea e Cea, porém, dada as características do afloramento, não foram identificadas macroformas significativas.

SEÇÃO AB-101 Localizada na BR-153, no trecho entre Comendador Gomes (MG) e Frutal (MG), a $20 \mathrm{~km}$ de Comendador Gomes (MG), a Seção AB-101 (Fig. 3) possui 130 metros de comprimento por 27 metros de espessura. Nessa seção predominam as fácies Aea, Aet, Aeh e Cea, e ocorrem superfícies de $1^{\mathrm{a}}, 2^{\mathrm{a}}, 3^{\mathrm{a}}$ e $4^{\mathrm{a}}$ ordem. Todas essas superfícies apresentam características semelhantes àquelas observadas nas seções AB-03 e AB-62.

Na porção basal do afloramento, à direita, encontra-se um canal delimitado na base e no topo por duas superfícies de $4^{\mathrm{a}}$ ordem e composto pelas fácies Aea e Cea.

A porção médio-superior da seção é caracterizada por uma série de superfícies de $3^{\mathrm{a}}$ ordem separadas em três estratos delimitados por três superfícies de $4^{\mathrm{a}}$ ordem. Essas superfícies são côncavas para o topo caracterizando macroformas do tipo canal (Elemento 2- $\mathrm{CH}, 3-\mathrm{CH}$ ), além de canais menores. As fácies predominantes nessa porção do afloramento são Aea, Cea e Aeh, sendo essa última, a principal constituinte do elemento 1-SB. Ainda nessa porção as superfícies de $2^{\mathrm{a}}$ ordem apresentam inclinações para SW em concordância com os rumos dos foresets das estratificações cruzadas que possuem direção média N 247 (Superfícies de $1^{\mathrm{a}}$ ordem), caracterizando macroformas de acréscimo à jusante (Elementos 1-DA, 2-DA, 3-DA e 4-DA). O topo da seção é marcado pela presença de dois elementos SB (2-SB e 3-SB) constituído pela fácies Aeh.

Em ambas as seções se observam que as macroforma de acréscimo à jusante (Elemento DA) variam de 1 a 2 metros de espessura por 7 a 15 metros de extensão. São constituídas por fácies arenosas e delimitadas na base e no topo por superfícies de $3^{\mathrm{a}}$ e $4^{\mathrm{a}}$ ordens.

As direções de paleocorrentes indicam fluxo de NW para SE, N para S e NE para SW, com padrão de dispersão divergente, porém, de norte para sul.

Canais (CH), barras (SG) e formas de leito cascalhentos (GB) Entre os elementos arquitetônicos o de maior escala é o canal principal $(\mathrm{CH})$. Esse se tiver largura superior a $10^{3}$ metros, somente pode ser identificado se houver grandes exposições e a superfície côncava for definida. Contido dentro desse elemento estão uma grande quantidade de canais menores e complexos de barras. Uma das características marcantes nos afloramentos da área de estudo é a presença de inúmeros canais menores com dimensões de até dezenas de metros. Basicamente, os grandes canais não são observados, sejam pela complexidade dos depósitos, ou pelas dimensões restritas afloramentos, que embora permitam a análise de macro, meso e microformas, não propiciam a observação de feições erosiva maiores, tais como o canal principal. As seções AB-47, AB-49 e AB-86 (Fig. 4) apresentam bons exemplos deste elemento arquitetônico.

Embora subordinado, o elemento LS ocorre muitas vezes associado no topo das seções AB-47 e AB-49, descritas abaixo. Esse elemento é caracterizado por depósitos arenosos (fácies Alp e Am) com bioturbações e geometria tabular e lenticular.

SEÇÃO AB-47 Localizada na Rodovia Itajá (GO)Caçú (GO), a $3 \mathrm{~km}$ de Itajá na subida da serra em direção a Caçú (GO), a seção AB-47 (Fig. 4) apresenta uma superfície de $5^{\text {a }}$ ordem, plana, que a divide em 2 segmentos, da base para o topo. Da base à porção média da seção ocorrem as fácies Cea, Alp e Am. Superfícies de $1^{a}$ ordem são representadas por estratificações plano-paralelas e cruzadas acanaladas de pequeno a médio porte, com rumo de paleocorrentes $\mathrm{N} 70$. As superfícies de $2^{\mathrm{a}}$ ordem são planas e extensas, e delimitam as fácies. As superfícies de $3^{\mathrm{a}}$ ordem são ausentes, enquanto que as superfícies de $4^{\mathrm{a}}$ ordem, planas ou suavemente convexas para o topo (Elementos 1LS e 2LS com canais menores associados) definem dois canais (elementos $1-\mathrm{CH}$ e 2-CH).

Duas superfícies de $4^{a}$ ordem dividem a seção em três, sendo que na porção inferior e média encontram-se dois elementos SB (formas de leito arenoso) caracterizados pelas fácies Am e Cea. A fácies Am nessa porção do afloramento é caracterizada por um arenito fino a médio, com seleção moderada, alguns vestígios de estratificações cruzadas e plano-paralelas, muitas marcas de raízes. A superfície de $4^{\mathrm{a}}$ ordem basal é caracterizada pela fácies Cea (elemento 1-CH).

A superfície de $4^{\text {a }}$ ordem na porção média do afloramento, suavemente côncava para o topo, caracteriza um canal (Elemento 2-CH). No segmento superior da seção, observa-se um grande número de superfícies de $2^{\mathrm{a}}$ ordem. As superfícies de $2^{\mathrm{a}}$ ordem são planas ou inclinadas segundo o rumo N 210 em média, e delimitam as fácies Cmg, Cea, Aea e Am. As superfícies de $3^{a}$ ordem são côncavas para o topo e se truncam mutuamente, formando um complexo de multicanais (elementos $\mathrm{CH}$ menores).

No topo da seção encontra-se um elemento LS marcado na base por uma superfície de $3^{\text {a }}$ ordem, côncava para cima e caracterizado pela fácies Aeh.

SEÇÃO AB-49 A seção AB-49 (Fig. 4) está localizada a $39 \mathrm{~km}$ de Quirinópolis (GO), na Rodovia Quirinópolis $(\mathrm{GO})$ - Rio Verde (GO). Apresenta um predomínio 


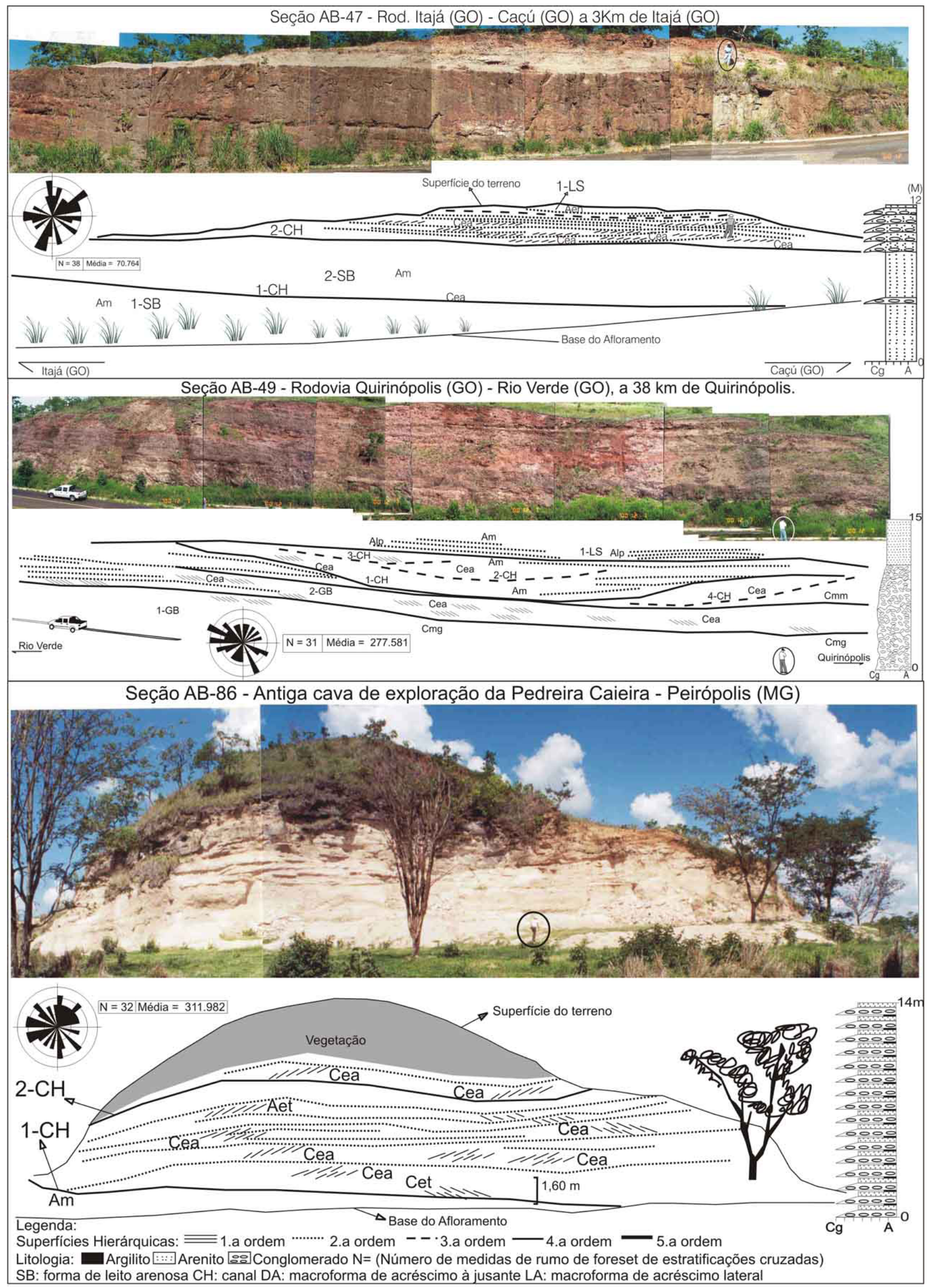

Figura 4 -Elementos arquitetônicos dos afloramentos AB-86, AB-49 e AB-109. 
das fácies Cea, Cmm, Cmg e Aea, e subordinadamente, Am e Alp. O afloramento é marcado por 4 superfícies de $4^{a}$ ordem, sendo 3 retilíneas ou com suave convexidade para o topo que delimitam duas formas de leito cascalhentos (elementos 1-GB e 2-GB), enquanto uma delas é côncava para o topo e delimita um grande canal (Elemento 1-CH) com 40 metros de extensão. Dentro do elemento 1-CH é possível observar muitos canais menores (elementos 2-CH e 3-CH) marcados por superfícies de $3^{a}$ ordem com forma côncava para o topo, truncadas no topo pelas superfícies de $4^{\mathrm{a}}$ ordem.

As superfícies de $2^{\mathrm{a}}$ ordem, planas ou com leve inclinação segundo o rumo N 240 em média, separam as litofácies e possuem geometria tabular. As superfícies de $1^{\text {a }}$ ordem ocorrem em grande número e são representadas por foresets de estratificações cruzadas acanaladas. As medidas do rumo de inclinação desses foresets indicam transporte de leste para oeste, principalmente para WNW (N 277,581).

A porção basal da seção é caracterizada por fácies conglomeráticas (Cea, $\mathrm{Cmm}, \mathrm{Cmg}$ ) que delimitadas pelas extensas superfícies de $4^{\mathrm{a}}$ ordem, constituem os elementos 1-GB e 2-GB (Barras cascalhentas).

$\mathrm{O}$ elemento 1-CH na parte média / superior do afloramento é constituído pelas fácies Cea e Am, e possui dois canais menores em seu interior (elementos 2-CH e 3-CH). Ainda nessa porção, à direita, outro canal menor (elemento 4-CH) delimita as fácies Cea e $\mathrm{Cmm}$.

No topo da seção encontram-se as fácies Alp e Am. A fácies Alp caracteriza um lençol de areia (elemento 1-LS). A fácies Am aparece no topo do elemento 1-LS com passagem gradacional e é caracterizada por um arenito fino a médio, com seleção fraca a moderada, e muitas marcas de raízes.

SEÇÃO AB-86 Localizada na antiga cava da Pedreira Caieira em Peirópolis (MG), a seção AB-86 (Fig. 4) possui 14 metros de altura por 60 metros de extensão. As fácies presentes nessa seção são: Aea, Cea, e Aet.

Duas superfícies de $4^{a}$ ordem dividem a seção em 2 estratos com aproximadamente 7 metros de espessura, e caracterizam dois grandes canais (elementos 1-CH e 2-CH). O interior desses estratos é marcado por um grande número de superfícies de $2^{\mathrm{a}}$ ordem. Essas superfícies delimitam conjuntos de fácies constituídos por Cea e Aea/Aet em ciclos granodecrescente ascendente. Possuem forma côncava para o topo e se truncam mutuamente formando um complexo de multicanais (Elementos $\mathrm{CH}$ menores). No interior dos estratos delimitados pelas superfícies de $2^{\text {a }}$ ordem ocorrem muitas superfícies de $1^{\text {a }}$ ordem representadas por foresets de estratificações cruzadas acanaladas e tabulares. As medidas dos rumos de inclinação desses foresets indicam grande dispersão do fluxo, porém, o valor médio indica fluxo para NW. Na base do afloramento ocorre a fácies Am, com 2 metros de espessura, granulometria média a grossa e muito bioturbado.

O topo dessa camada é cortado de forma erosiva por uma superfície abrupta, de $4^{\mathrm{a}}$ ordem, sobre a qual repousa o elemento 1-CH. A porção média da seção é caracterizada por vários estratos decimétricos, limitados na base e topo por superfícies planas, de $2^{\mathrm{a}}$ ordem, com as fácies Cet, Cea e Aet. No topo da seção outra superfície de $4^{\mathrm{a}}$ ordem com forma plana trunca abruptamente o topo do elemento 1-CH, caracterizando outro canal maior (elemento 2-CH) composto pela fácies Cea.

\section{Macroformas de acréscimo lateral (LA) e formas} de leito arenosas (SB) Ao contrário das macroformas de acréscimo à jusante (DA), as macroformas de acréscimo lateral (LA) foram identificadas apenas em alguns afloramentos na área de estudo (seções AB-48 e AB- 109 - Fig. 5). Suas características morfológicas são semelhantes às encontradas no elemento DA.

SEÇÃO AB-48 Na seção AB-48 (Fig. 5) ocorrem principalmente superfícies de $1^{\mathrm{a}}, 2^{\mathrm{a}}$ e $3^{\mathrm{a}}$ ordem. As superfícies de $1^{\text {a }}$ ordem são representadas por planos inclinados de estratificações cruzadas com rumo N 137. As superfícies de $2^{\mathrm{a}}$ ordem são suavemente inclinadas e delimitam as fácies Cea, Cmm e Aea.

As superfícies de $4^{a}$ ordem ocorrem na porção média e no topo da seção. A mais inferior delimita o topo de um complexo de canais menores (elementos 2- $\mathrm{CH}, 3-\mathrm{CH}$ ), e a base de um canal maior (elemento $1-\mathrm{CH})$ com vários canais menores (elementos $4-\mathrm{CH}$ e 5-CH). Na porção superior da seção a outra superfície de $4^{\mathrm{a}}$ ordem trunca superfícies de $3^{\mathrm{a}}$ e $2^{\mathrm{a}}$ ordem.

No canal maior (elemento 1-CH) definido entre as duas superfícies de $4^{\mathrm{a}}$ ordem, também se encerra um conjunto de superfícies de $2^{\mathrm{a}}$ ordem que definem dois elementos LA (mesoformas de acréscimo lateral) com inclinação para SW (N 190).

O conjunto de fácies encontradas nessa seção é caracterizado pelas fácies Cea e, subordinadamente, Alp no topo. As estratificações cruzadas acanaladas (superfícies de $1^{\text {a }}$ ordem) apresentam indicação de paleocorrete para N 270 e N 90.

SEÇÃO AB-109 A seção AB-109 (Fig. 5) está localizada na Rodovia Campina Verde (MG) - Comendador Gomes (MG) a $5 \mathrm{~km}$ de Campina Verde (MG). Possui 110 metros de extensão por 23 metros de altura, expondo as fácies Am, Cmm, Aea e Cea.

$\mathrm{O}$ afloramento é marcado por 3 superfícies de $4^{\text {a }}$ ordem, planas ou com suave concavidade para cima, que dividem a seção em 3 segmentos. Na porção basal a superfície de $4^{\mathrm{a}}$ ordem delimita o topo de um estrato de arenito maciço (fácies Am), com camadas conglomeráticas (elemento 1-SB).

Na porção intermediária, as superfícies de $4^{\mathrm{a}}$ ordem delimitam um estrato areno-conglomerático (fácies Cea, Cmm e Aea) onde se concentram as superfícies de $3^{\mathrm{a}}$ e $2^{\mathrm{a}}$ e $1^{\mathrm{a}}$ ordens. Nessa porção são encontrados 3 mesoformas de acréscimo lateral (elementos 1-LA, 2-LA e 3-LA) internamente ao canal principal (elemento 1-CH com ângulo de mergulho em torno $17^{\circ}$ graus e rumo $\mathrm{N}$ 20 , fazendo ângulo maior que $60^{\circ}$ em relação às medi- 


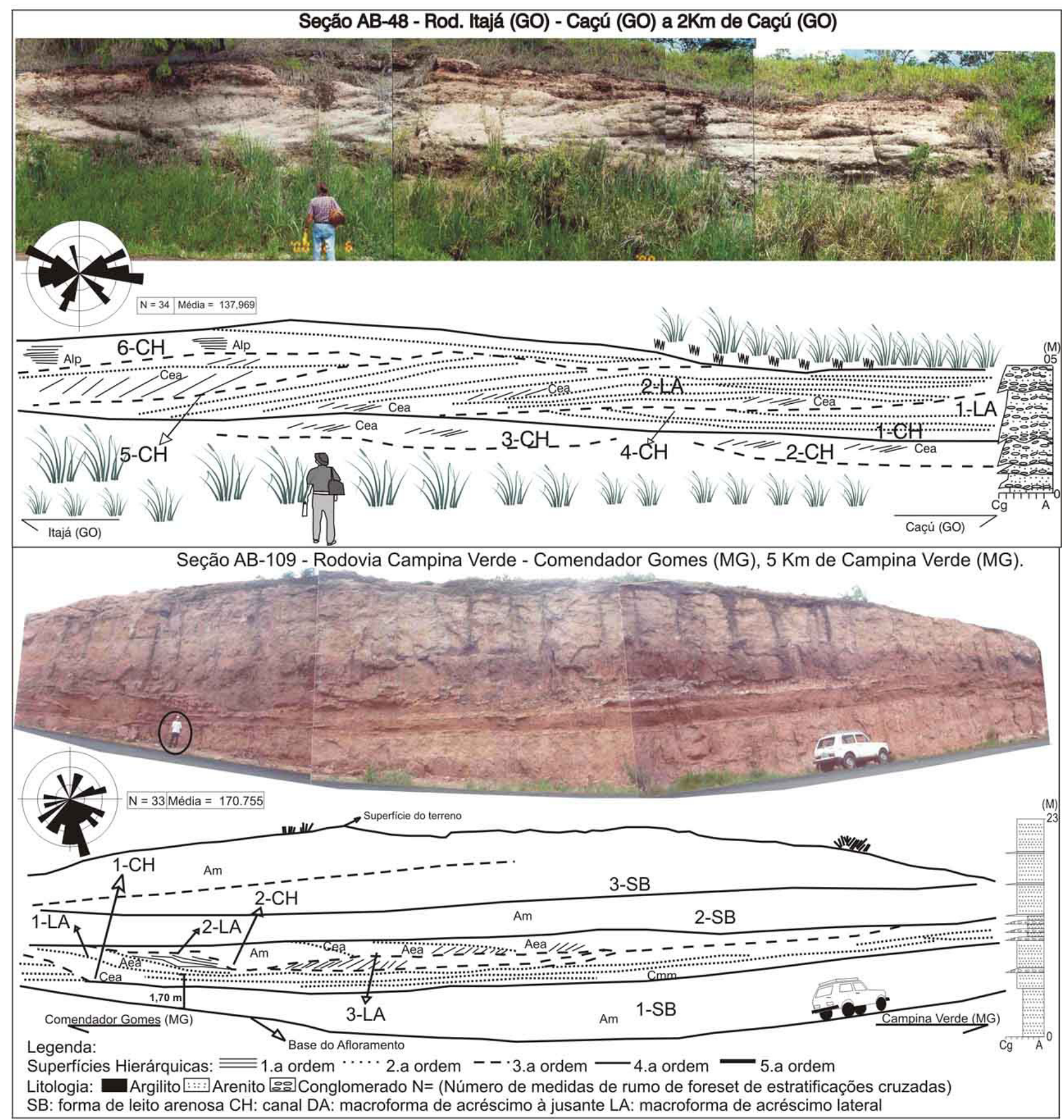

Figura 5 -Elementos arquitetônicos dos afloramentos AB-47, AB-48.

das de rumos dos foresets das estratificações cruzadas que são de N 170,00). Além desses elementos também ocorre o elemento 2-CH (canal menor com eixo N 20) irregular e com forma côncava para o topo.

Na porção superior a superfície de $4^{\mathrm{a}}$ ordem delimita a base de um estrato arenoso maciço (fácies Am e $\mathrm{Cmm}$ ), semelhante ao estrato basal. Essa superfície de $4^{\mathrm{a}}$ ordem possui forma plana e trunca algumas superfícies de menor ordem. O topo da seção é marcado por um paleosolo com $40 \mathrm{~cm}$ de espessura.

No interior dessas macroformas de acréscimo lateral (elemento LA) as superfícies de $2^{\mathrm{a}}$ ordem marcam os limites de estratos arenosos com até $40 \mathrm{~cm}$ de espessura, e normalmente, possuem inclinação acompanhado a geometria externa da mesoforma. As superfícies de $2^{\mathrm{a}}$ ordem também possuem inclinações suaves e delimitam pequenos ciclos granodecrescentes ascendentes, tabulares, com espessura de até $30 \mathrm{~cm}$.

As superfícies de $1^{\text {a }}$ ordem se concentram na porção média do afloramento. São representadas por estratificações cruzadas acanaladas de pequeno porte (até 1 metro de comprimento por $40 \mathrm{~cm}$ de altura), com direções de paleocorrente variando de SW para SE.

Paleocorrentes A medição sistemática do rumo de inclinação dos foresets de estratificações cruzadas em 
diversos pontos da área de estudo possibilitou a confecção de um mapa de paleocorrentes (Fig. 6).

Os vetores médios apresentam grande dispersão e indicam oscilação na direção dos fluxos, sugerindo grande dinâmica fluvial na porção norte e nordeste da Bacia Bauru, durante sua evolução.

Observa-se que na porção noroeste da área as paleocorrentes possuem caráter centrípeto indicando transporte para oeste (pontos AB-49 e AB-50) e para leste (pontos $\mathrm{AB}-47$ e $\mathrm{AB}-48$ ), possivelmente associado à região proximal do sistema de leque.

$\mathrm{Na}$ região central da área de estudo as paleocorrentes indicam transporte para sul/sudoeste predominantemente, enquanto que na porção leste as paleocorrentes indicam transporte para sudoeste.

Todas essas medidas indicam que a Bacia Bauru foi preenchida por fluxos que vinham de 2 regiões: uma a norte na Província Alcalina de Goiás, e outra a nordeste na região do Soerguimento do Alto Paranaíba. Essa hipótese é evidenciada por dados de petrografia dos arenitos do Grupo Bauru apresentados por Batezelli (2003) e Batezelli et al. (2005), onde constataram similaridades mineralógicas com ambas as regiões acima mencionadas.

MECANISMOS DEPOSICIONAIS E RECONSTRUÇÃO PALEODEPOSICIONAL As boas exposições dos depósitos do Grupo Bauru na porção norte da bacia possibilitaram a identificação de vários elementos arquitetônicos cujas características permitem, não apenas a reconstrução paleogeográfica da área, como também a definição dos estilos fluviais e suas características hidráulicas.

As macroformas de acréscimo a jusante (elemento DA), constituídas pelas fácies Cea, Aea e Aet, são formadas a partir da migração de grandes barras areno-conglomeráticas a no canal fluvial principal. A geração dessas macroformas está associação a fluxos de alta energia que permitem que os grandes foresets de dunas arenosas migrem por dezenas de metros de forma assintótica (com base tangencial ou planar) (Fig. 7). Segundo Miall (1996) esse elemento é diagnóstico de rios entrelaçados com baixa sinuosidade.

$\mathrm{Na}$ área estudada, as macroformas de acréscimo à jusante (elemento DA - Fig. 3) ocorrem associadas a outros elementos arquitetônicos em depósitos arenosos, tais como o elemento SB (formas de leito arenoso). As formas de leito arenoso (elemento SB), constituídas pelas fácies Alp e Am, com ou sem marcas onduladas e estratos cruzados (fácies Aea e Aet). Esse elemento é formado a partir de fluxos laminados de alta energia que favorecem a migração de barras arenosas sob a forma de extensos lençóis à jusante (Miall, 1996).

As macroformas de acréscimo lateral (elemento LA) aparecem apenas em dois pontos da área. Sua origem está relacionada a porções do canal fluvial onde os fluxos principais são dirigidos contra um banco de sedimentos, principalmente em uma curva, e a forças centrípetas conduzem ao desenvolvimento de uma turbulência ("rebojo") helicoidal, gerando uma corrente

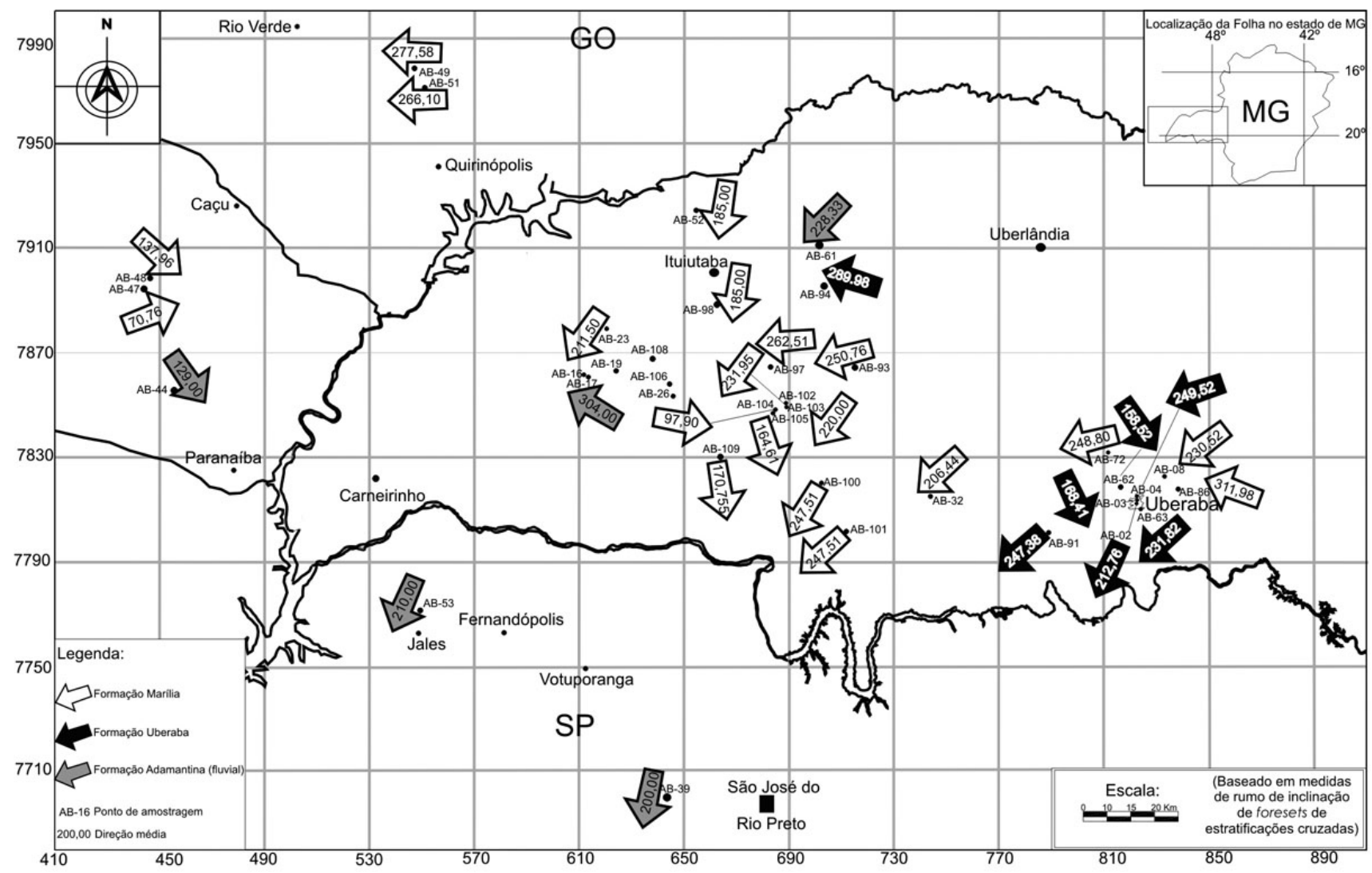

Figura 6 - Mapa de Paleocorrentes do Grupo Bauru no Triângulo Mineiro e áreas adjacentes. 


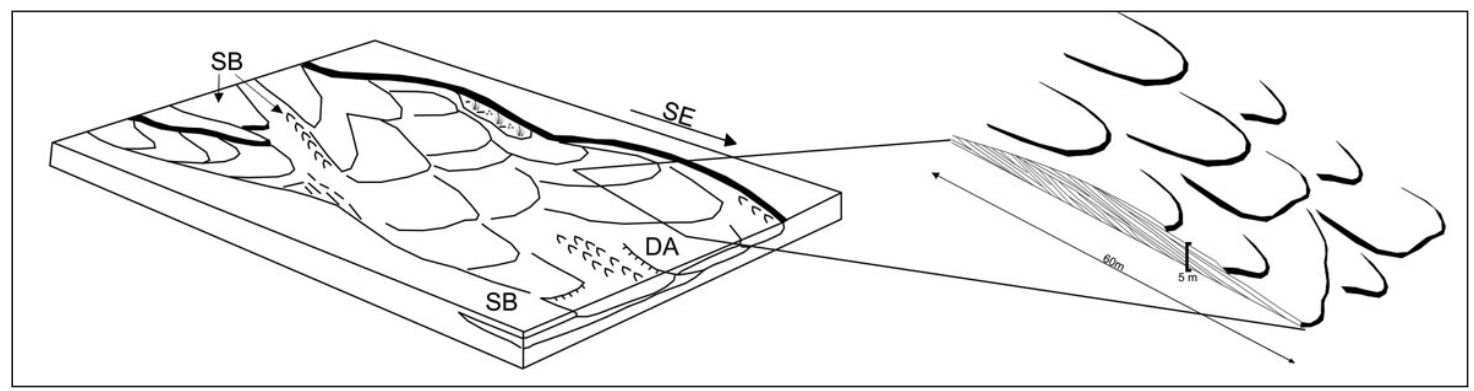

Figura 7 - Modelo esquemático da gênese de uma macroforma de acréscimo à jusante em um canal fluvial tipo entrelaçado (Miall, 1996 - Modificado).

oblíqua a esse banco. Dessa forma, a redução do stress torna essa porção do canal um local favorável à deposição e o banco é acrescido lateralmente em direção perpendicular ao fluxo principal do canal (Miall, 1985; 1988a e b; 1996) (Fig. 8). Freqüentemente essas macroformas apresentam seu topo com terminações em offlap, e sua base em downlap erosivo. As fácies encontradas na área de estudo permitem classificá-las em macroformas de acréscimo lateral areno-cascalhentas (Miall, op. cit.).

O fato das macroformas de acréscimo lateral serem restritas na área de estudo sugere que os canais fluviais possuíam baixa sinuosidade.

A distinção entre as formas de leito arenosas (elemento SB) e as macroformas arenosas de foreset (elemento FM) depende da escala e qualidade dos afloramentos (Miall, 1985; 1988a e b; 1996). O elemento SB inclui extensos campos de marcas onduladas e dunas menores (fácies Aeh, Aea e Aet) cuja gênese está relacionada ao desenvolvimento de barras formadas a partir da migração de formas de leito de canal a jusante, ou ao topo de barras formadas por fluxos em lençol de leques de arrombamento (crevasse splays).

O elemento LS, constituído pelas fácies Alp e Am, representam depósitos extra canal gerados em pe- ríodos de enchente. São saias de areia laminadas que podem estar associadas a depósitos de overbank (elemento OF) formados em planícies de inundação ou em canais abandonados por fluxos esporádicos. Em depósitos proximais de leques aluviais esse elemento pode estar associado ao elemento SG (formas de leito cascalhentos) (Miall, 1985; 1988a e b; 1996).

Na seção AB-47 o elemento LS fica evidente, pois é marcada em sua base por uma superfície de $3^{\mathrm{a}}$ ordem côncava para cima, sobrepondo-se a um paleosolo (fácies Am) indicando deposição extra-canal, ou mesmo um hiato deposicional (Fig. 13). Batezelli (2003) e Batezelli et al. (2005) através da análise petrográfica em amostras dessa mesma seção, constataram a presença de argila mecanicamente infiltrada, resultante de transporte por fluxos aquosos em períodos de enchentes esporádicas (sieve effect).

Os canais menores (elementos $\mathrm{CH}$ ) identificados na área de estudo ocorrem associados a todos os demais elementos, em diferentes escalas.

Canais maiores (elemento de $\mathrm{CH}$ - intermediário) são marcados por superfícies de $4^{\mathrm{a}}$ ordem com suave concavidade para o topo enquanto que os canais menores, geralmente são delimitados por superfícies de $3^{\mathrm{a}}$ ordem. Nesse caso, além da dimensão, a associação

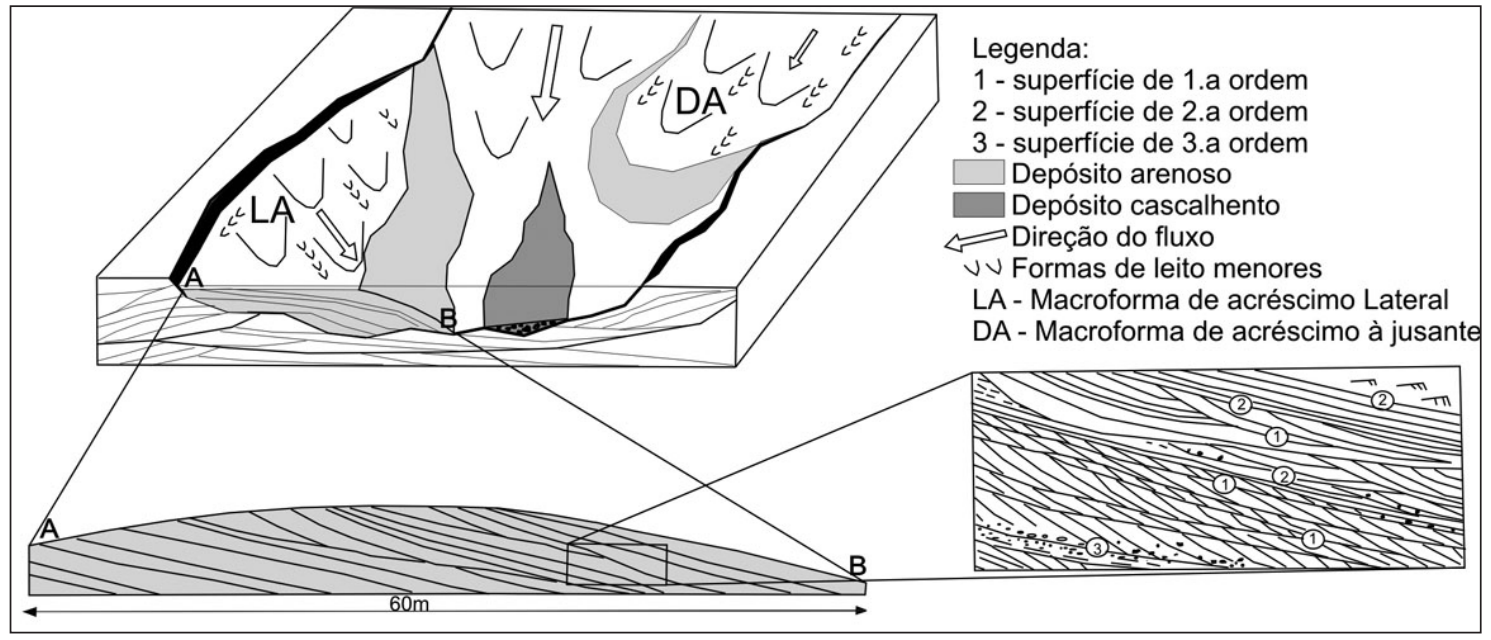

Figura 8 - Modelo esquemático de uma macroforma de acréscimo lateral em depósito fluvial tipo entrelaçado. 
faciológica e os elementos arquitetônicos menores permitiram identificar os diferentes tipos de canais na área de estudo (Fig. 9).

A associação de fácies $\mathrm{Cmm}$ e $\mathrm{Cmg}$ com gradação normal ou inversa, em camadas espessas são características de fluxos de massa e fluxos de detritos associados a eventos de sedimentação rápida e de alta energia (processos gravitacionais), encontrada principalmente no elemento GB (Figs. 6 e 10).

Essas características são comuns de depósitos proximais de leques aluviais, onde a inclinação é maior que $5^{\circ}$ (Galloway \& Hobday, 1983) (Figs. 11 e 12). Quando as fácies $\mathrm{Cmm}$ e $\mathrm{Cmg}$ são pouco espessas (< 1 metro), associadas à base de grandes lentes arenosas (fácies Am > 1 metro) podem ser interpretadas como depósitos de fluxos canalizados de porção proximal a intermediária de leques aluviais. As fácies Ceag e Ceam frequentemente ocorrem associadas as fácies $\mathrm{Cmm}$ e $\mathrm{Cmg}$, no elemento $\mathrm{GB}$, nas porções proximais a intermediárias de leques aluviais, onde o fluxo é menos viscoso, com formação de depósitos canalizados. No entanto, quando pouco espessas ( $<1$ metro), formando corpos lenticulares e feições acanaladas associadas às fácies Am, Aea e Aet, são interpretadas como depósitos tipo lag, que é uma feição típica de depósitos de barras longitudinais de ambiente fluvial (Miall, 1985, 1988a e b). Essas feições normalmente se desenvolvem em ambiente fluvial tipo entrelaçado nas porções intermediárias e distais de sistemas aluviais (Figs. 11 e 12).

$\mathrm{Na}$ região de Quirinópolis (GO), a fácies Cea está associada às fácies $\mathrm{Cmm}, \mathrm{Cmg}$, $\mathrm{Am}$ e Aea, formando um estrato com mais de 20 metros de espessura (Fig. 5). Nesse ponto são comuns feições deformacionais (injeções de areia), gradações normais e inversas, indicativas de processos gravitacionais. As estratificações cruzadas acanaladas dessa fácies são típicas de depósitos de barras clastosas longitudinais (Miall, 1985; 1988a e b; 1996) (Fig. 10).
A fácies Aea pode ser gerada em vários ambientes no sistema aluvial. Associada as fácies Ceam e Cmg em ciclos granodecrescentes ascendentes, essa fácies é típica de depósitos de preenchimento de canais ativos. As fácies Ceag e Cea em sucessões com granodecrescência ascendente podem representar depósitos de canais ativos com baixa taxa de migração lateral (Ramos \& Sopeña, 1983; Miall, 1985; 1988a e b; 1996), com diminuição gradual de energia em direção ao topo da seqüência, típicas de ambiente fluvial entrelaçado, em porções mais distais do sistema de leques.

A fácies Am normalmente ocorre em espessos estratos (>2 metros) com forma lenticular, por vezes amalgamadas, com clastos dispersos e icnofósseis do tipo tubos verticais (marcas de raiz). É comum a associação com as fácies $\mathrm{Cmm}$ e $\mathrm{Cmg}$. É interpretada como depósito de barra arenosa transportada por fluxo de massa pouco viscoso sob condições de alta energia, em porções intermediárias a distais do sistema de leques (elementos SB). A falta de estruturas sedimentares é explicada pela exposição subaérea dessas barras em porções mais distais do leque, permitindo assim o desenvolvimento de calcretes pedogenéticos, obliterando as estruturas primárias. Batezelli (2003) e Batezelli et al. (2005) constataram essas feições em análise petrográfica.

A sucessão de fácies $\mathrm{Cmm}$ e $\mathrm{Cmg}$ na base de espessas seqüências de Am (com tubos no topo), com repetição cíclica indica pulsos de sedimentação esporádica. Ao fim de cada ciclo, haveria um período em que os sedimentos ficariam expostos aos efeitos do intemperismo e atividade de organismos (plantas). No ciclo seguinte, outra sucessão de fácies Cmm, Cmg e Am se depositaria sobre o anterior, e assim sucessivamente, gerando espessos estratos.

Os dados de paleocorrentes das fácies Aea e Aet, que indicam transporte sedimentar de leste/nordeste para oeste/sudoeste na porção oriental do Triângulo

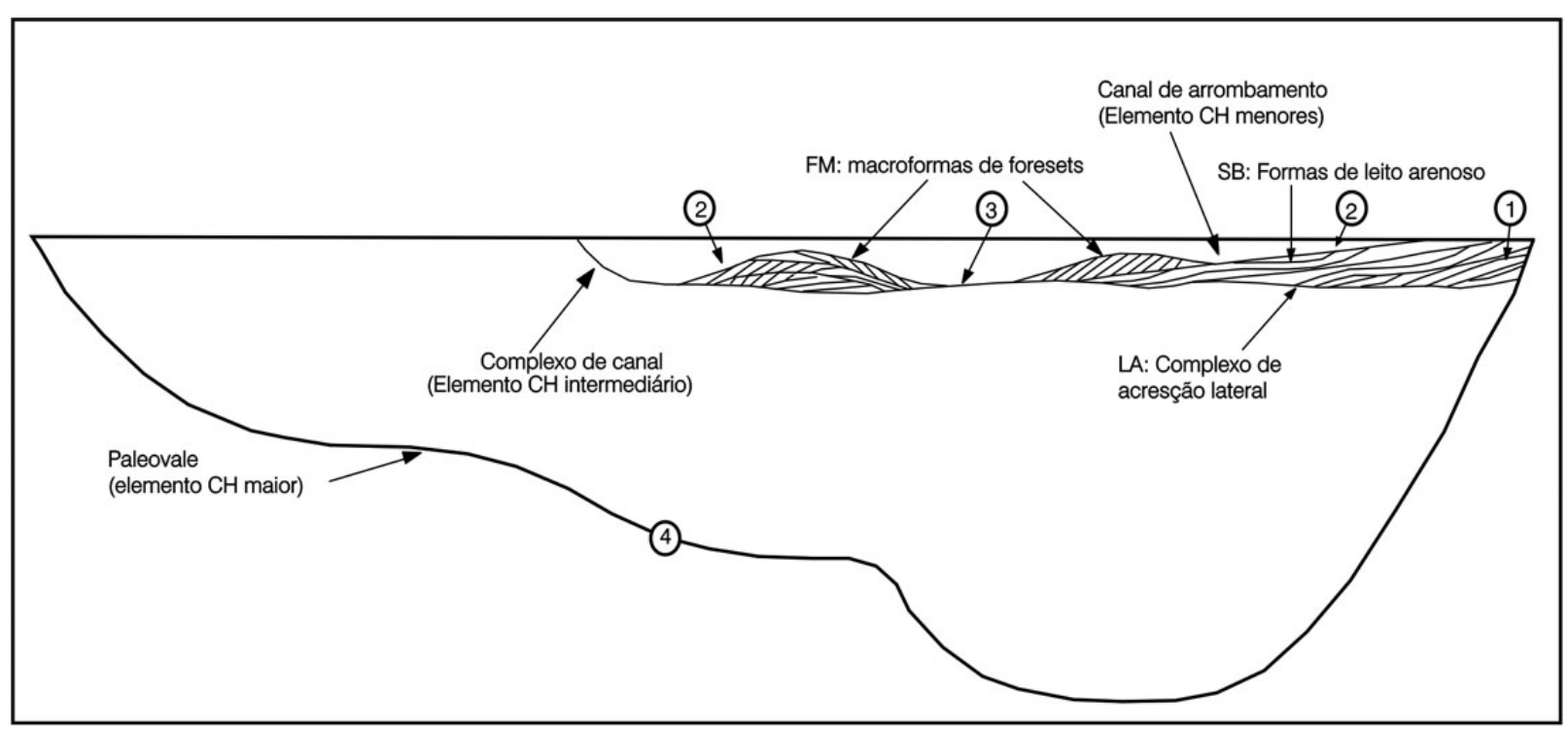

Figura 9 - Hierarquia dos elementos. Notar posicionamento dos canais menores e complexos de barras com canal principal (Miall, 1985). 


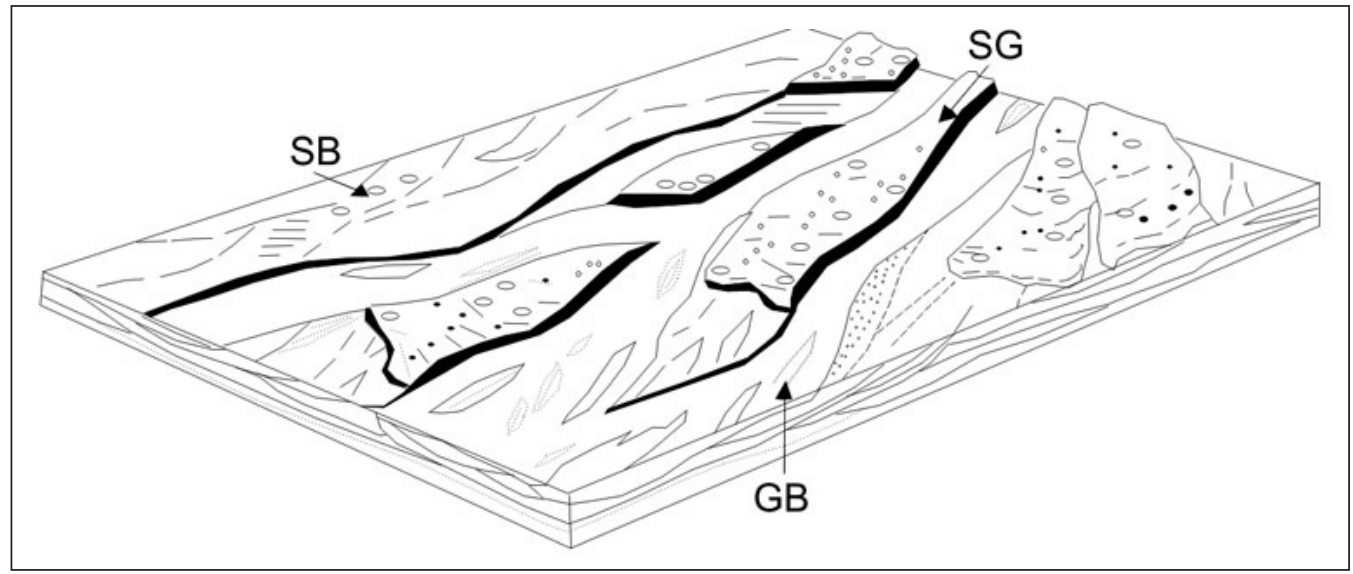

Figura 10 - Modelo esquemático da construção dos elementos GB (Barras cascalhentas) e SG (Depósitos formados por fluxos gravitacionais) (Miall, 1996).

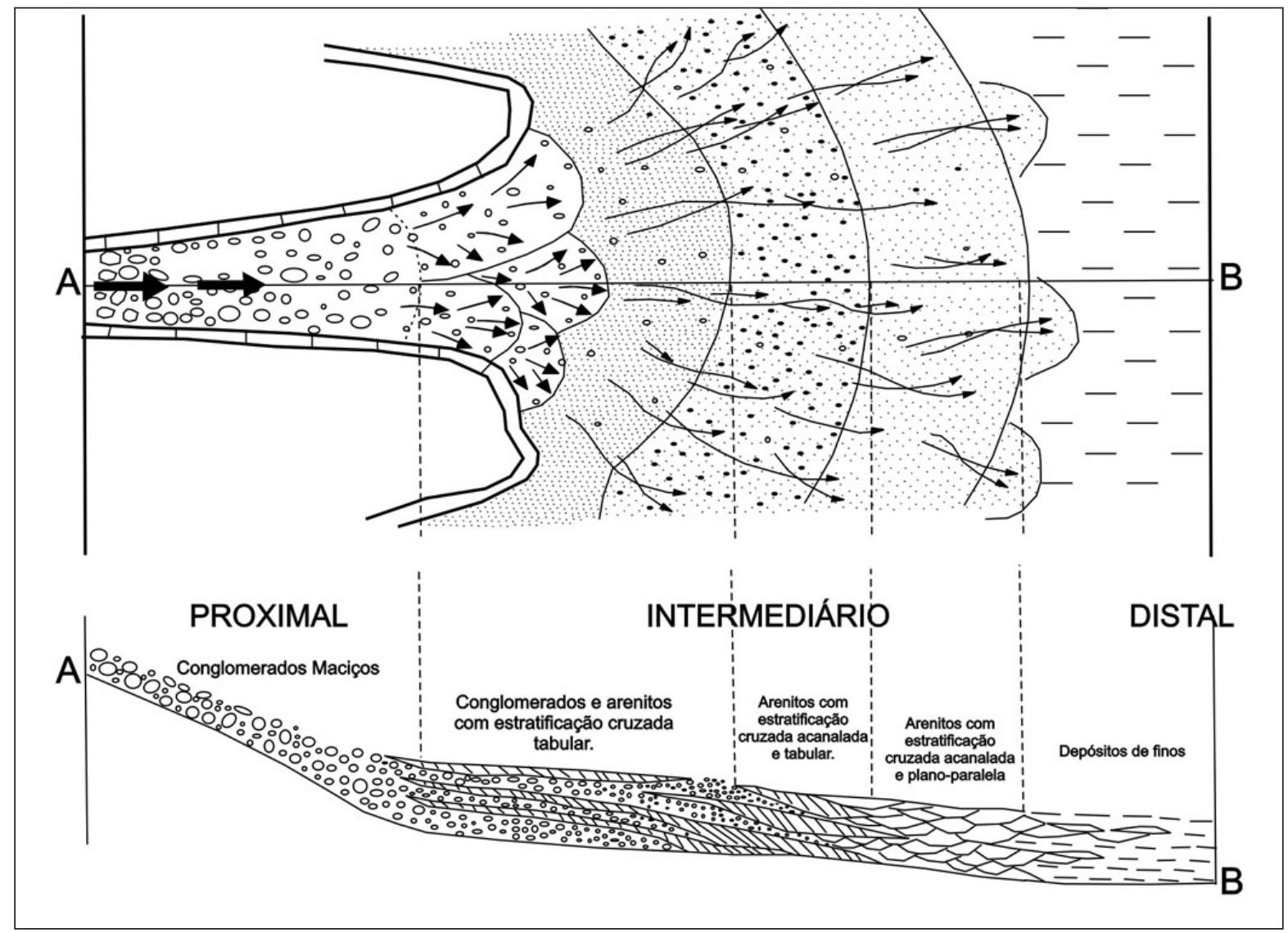

Figura 11 - Visão em planta e perfil longitudinal idealizado de um sistema de leque aluvial com a distribuição granulométrica em função da distância com a área fonte. (Galloway \& Hobday, 1983 Modificado).

Mineiro, e de norte/noroeste para sul/sudeste na porção setentrional da área de estudo (Fig. 6), sugerem que o nível de base se localizava na porção centro sul da bacia.

A alta dispersão das paleocorrentes, as fácies e os elementos arquitetônicos identificados nas seções mostram deposição em um sistema de leques aluviais, dominados por rios entrelaçados com baixa sinuosidade, conforme o conceito proposto por Stanistreet \&
McCarthy (1993).

Os elementos arquitetônicos dos depósitos arenosos do Grupo Bauru se assemelham muito aos descritos por Bromley (1991), na Formação Kayenta, no Colorado (USA) e aos depósitos da Formação Rio Vero, nos Pirineus, Espanha, descritos por Jones et al. (2001), ambos associados a porções intermediárias a distais de sistemas de leques aluviais.

O modelo deposicional aqui proposto é muito 


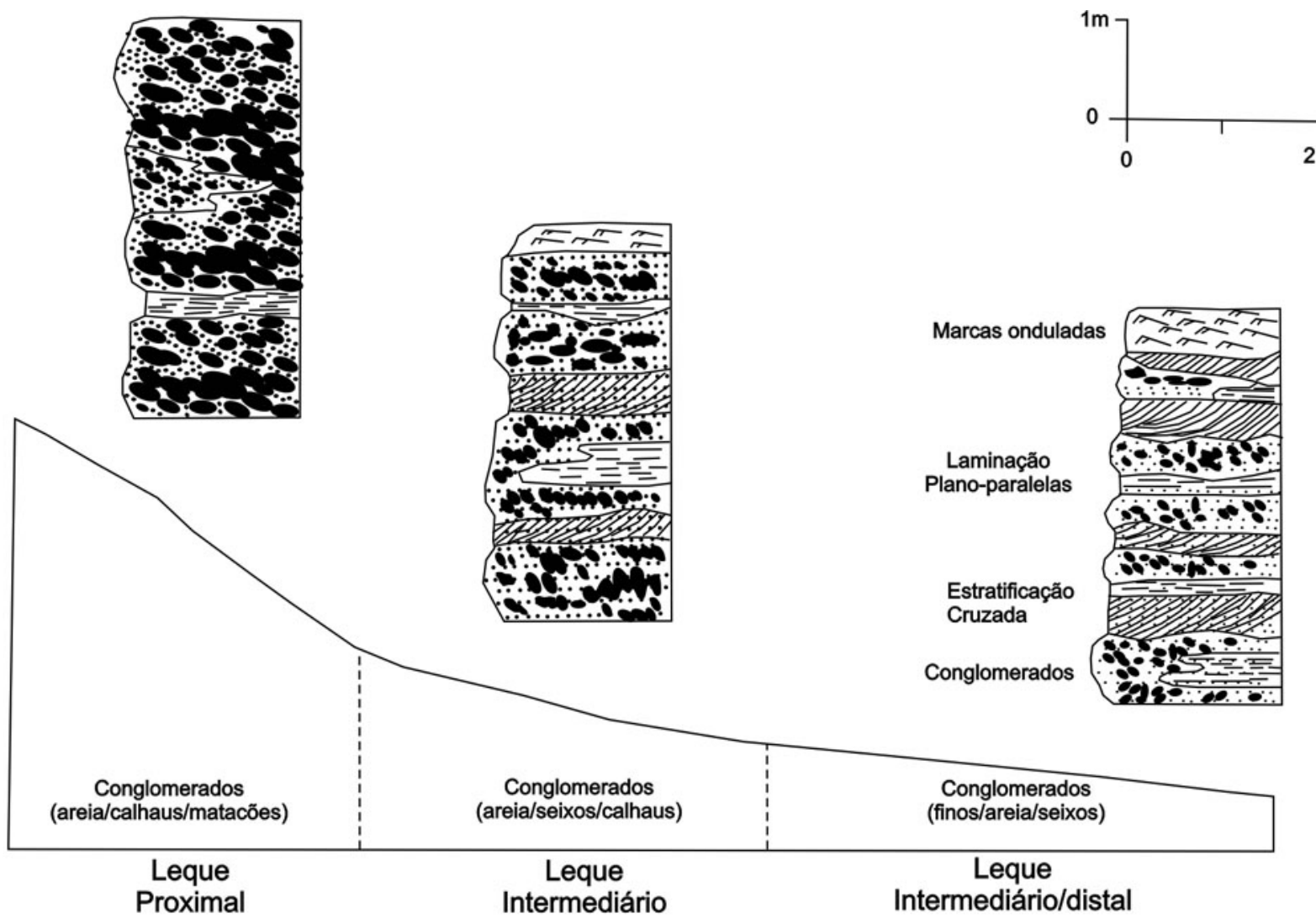

Figura 12 - Diminuição do tamanho dos clastos de um leque, acompanhando a redução do gradiente (Galloway \& Hobday, 1983).

semelhante com o sistema aluvial Huesca, na Bacia de Ebro (Espanha), onde os canais fluviais entrelaçados possuem caráter distributário, evoluindo a partir de leques que adentram a bacia de sul para norte, vindos dos Pirineus (Hirst, 1991).

A paleogeografia do Grupo Bauru compreenderia ainda, um sistema lacustre que funcionava como nível de base para a sedimentação desses leques, e retrabalhamento eólico ao longo das planícies (Fig. 14).

FÁCIES, ELEMENTOS ARQUITETÔNICOS E PALEOCORRENTES: SEUS SIGNIFICADOS NA EVOLUÇÃO DA SEQÜÊECIA ALUVIAL NEOCRETÁCEA O significado da palavra fácies tem sido muito discutido na comunidade geológica desde a década de 40 por diversos autores (como por exemplo: Moore, 1949; Teichert, 1958; Krumbein \& Sloss, 1963; Walker, 1984, Miall, 1984; Reading, 1996). Atualmente, o termo fácies é usado tanto para exprimir caráter descritivo como interpretativo para rocha.

A partir do reconhecimento das fácies e conjunto de fácies que compõem as unidades do Grupo Bauru na área de estudo, e, da análise de elementos arquitetônicos, constatou-se que os mecanismos deposicionais atuantes foram predominantemente marcados por fluxos laminares de alta energia, e subordinadamente, fluxos gravitacionais. A associação das fácies $\mathrm{Cmg}, \mathrm{Cmm}$, Ceag, Cetg, Ceam e Am (elementos CH e SG) é indicativa de processos fluviais atuantes em planícies alu- viais, relacionados a fluxos gravitacionais canalizados ou não, nas porções proximais de leques. Afloramentos com a associação Ceam, Am, Aea, Aet, Aeh (elementos DA e SB) indicam porções intermediárias a distais dos sistemas de leques onde os sedimentos foram transportados por correntes fluviais, perenes ou efêmeras, através de canais entrelaçados com baixa sinuosidade ou sob a forma de lençóis de areia.

Os depósitos estudados correspondem à porção estratigráfica mais superior do Grupo Bauru e registram uma mudança nos mecanismos sedimentares da bacia, quando comparado às unidades mais basais. Embora não tenham sido encontradas superfícies regionais que possam indicar limites de seqüências, as variações faciológicas podem ser entendidas como um novo ciclo sedimentar, dentro da Seqüência Neocretácea, sobretudo por revelar informações sobre a taxa de acomodação, nível de base e aporte sedimentar.

A análise de seqüências estratigráficas em depósitos fluviais teve início com o trabalho de Allen (1974), que desenvolveu uma série de modelos de estratigrafia aluvial baseada em raciocínios dedutivos simples. Através da identificação de superfícies chaves, muitos autores desenvolveram metodologias para o estudo de seqüências estratigráficas continentais, sobretudo àquelas próximas a linha de costa (e.g. Posamentier et al., 1988; Van Wagoner et al., 1990; Shanley \& McCabe, 1991; Shanley \& McCabe, 1993; Shanley \& McCabe, 1994 e Currie, 1997). 

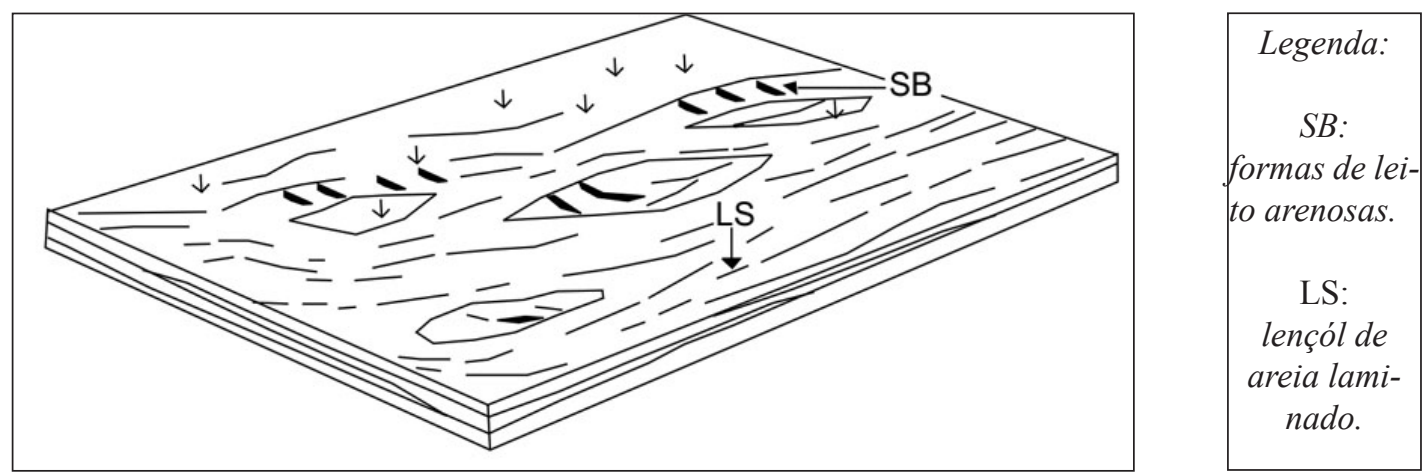

Figura 13 - Modelo da arquitetura deposicional de um fluxo arenoso em lençol (sheetflood) em rios efêmeros associado ao elemento SB (Miall, 1996).

Por causa da falta de correlação com depósitos costeiros, o presente trabalho elege a terminologia proposta por Martinsen et al. (1999) para explicar a evolução da seqüência neocretácea da Bacia Bauru. Naquele trabalho, os autores sugerem os tratos de sistemas de baixa e alta de acomodação (low-e high-accommodation system tracts) baseada nas razões entre a taxa de acomodação da bacia aluvial e a taxa de suprimento sedimentar.

Os tratos são delimitados pelos limites de seqüência e por uma zona ou superzona de expansão (expansion surface) intermediária, caracterizada pelo predomínio de litofácies pelíticas. A geração das superfícies limítrofes e os estilos deposicionais distintos de cada trato são interpretados devido variações do nível de base estratigráfico, expresso pela relação entre espaço de acomodação (A) e suprimento sedimentar (S). Os limites de seqüências são gerados durante as fases de abrupta redução ou aumento de espaço de acomodação, quando a razão A/S passa a ser zero (0) ou negativa, condições que provocam a ocorrência de bypass sedimentar e a formação de extensivas superfícies de erosão, conforme observado no limite Caiuá / Bauru por Batezelli et al. (2003).

Nesse sentido, o trato de baixa taxa de acomodação é representado pelos depósitos lateralmente contínuos de canais fluviais amalgamados (sheets), multiepisódicos e multilaterais, do "Intervalo A" (Batezelli et al., 2003), gerados quando a razão $\mathrm{A} / \mathrm{S}$ é positiva, mas inferior à unidade (1), resultando no preenchimento de todo o espaço disponível e eventual bypass sedimentar.

Quando a razão A/S aumenta abruptamente, atingindo a unidade, ocorre o desenvolvimento de depósitos finos, regionalmente expressivos (superfícies de expansão) que delimitam superiormente o trato de baixa taxa de acomodação, demarcando mudanças significativas nos estilos aluviais. No estágio inicial de sedimentação na Bacia Bauru o aumento da razão A/S foi muito elevada, provavelmente superior a 1 , o que fez com que o espaço disponível fosse maior que o aporte sedimentar. Essa feição é representada pelos depósitos lacustres da Formação Araçatuba e caracteriza o início do trato sistema de alta taxa de acomodação. A subse- qüente estabilização do nível de base estratigráfico e progressivo aumento no suprimento sedimentar favoreceu a implantação de um sistema fluvial meandrante psamítico (Formação Adamantina) que passou a colmatar essa bacia endorréica.

O aumento no aporte sedimentar causado pelos constantes pulsos de elevação das bordas da Bacia Bauru a norte (Província Alcalina de Goiás) e a nordeste (Soerguimento do Alto Paranaíba), associado à progressiva diminuição do espaço de acomodação fez com que sedimentos aluviais progradassem sobre os depósitos finos originando uma nova fase de sedimentação que caracteriza um trato de sistema de baixa taxa de acomodação (formações Uberaba e Marília).

A passagem de um ambiente com grande espaço de acomodação sedimentar e baixa taxa de sedimentos para um ambiente dominado por depósitos aluviais em que o aporte sedimentar foi muito grande quase que preenchendo todo o espaço de acomodação, indica grande atividade de soerguimento da área fonte. Assim sendo, a arquitetura aluvial definida para o estágio final de sedimentação da Bacia Bauru permite enquadrar os depósitos aluviais descritos em um trato de sistema de baixa taxa de acomodação. A figura 15 é uma proposta de modelo da arquitetura deposicional baseada nas informações levantadas e em dados de Batezelli (2003).

Embora não tenham sido encontradas superfícies que indicam limites entre as formações Araçatuba/ Adamantina e Uberaba/Marília, os depósitos descritos registram um incremento nos processos aluviais ocorrido após da fase lacustre/fluvial (Batezelli, 2003) da Bacia Bauru, marcando o aumento na taxa de sedimentação e diminuição da taxa de acomodação. Segundo Posamentier et al. (1988) e Posamentier \& Allen (1993a e b), as unidades representadas por depósitos de canais com corpos arenosos multilaterias e grande extensão em área representam baixas taxas de subida do nível estratigráfico.

A identificação de paleosolos (fácies Am) aponta uma nova perspectiva para os estudos sobre Estratigrafia de Seqüências da Bacia Bauru. A exemplo dos trabalhos de McCarthy \& Plint (1998), McCarthy et al. (1999) e Plint et al. (2001), a caracterização micromorfológica de espessos perfiz de paleosolos em depósitos 


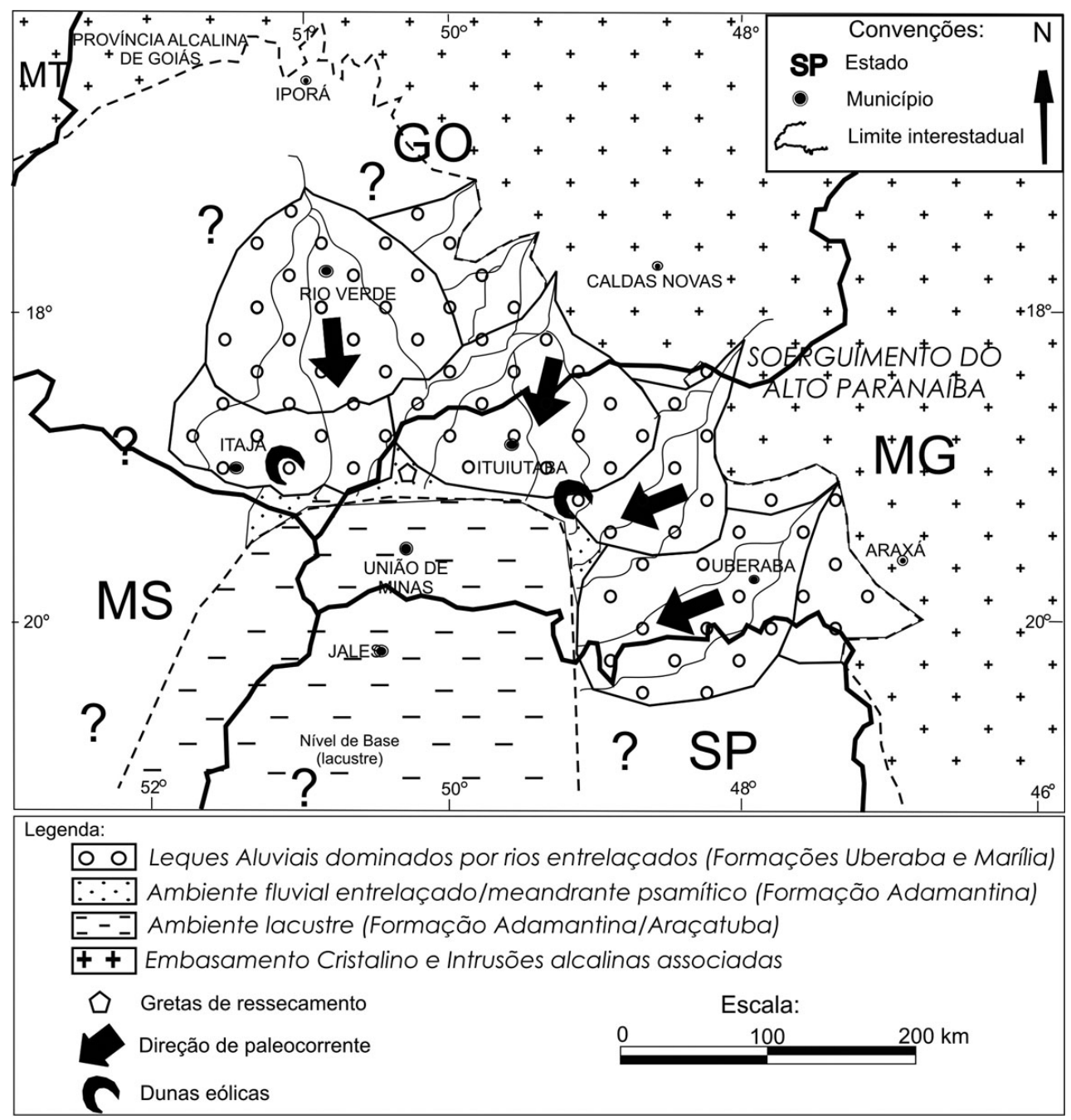

Figura 14 - Distribuição paleogeográfica dos ambientes que coexistiram na fase inicial de sedimentação da Bacia Bauru.

continentais poderão revelar com maior exatidão quais processos atuaram na evolução da bacia, sua relação com as variações do nível do freático, espaço de acomodação subaéreo, além do reconhecimento de interflúvios que correspondam a superfícies limítrofes mais detalhadas.

As características faciológicas, os elementos arquitetônicos e as paleocorrentes da área de estudo indicam que o aumento no aporte sedimentar foi causado por constantes pulsos de elevação das bordas da Bacia Bauru a norte (Província Alcalina de Goiás) e a nordeste (Soerguimento do Alto Paranaíba). Associado à progressiva diminuição do espaço de acomodação houve a colmatação da bacia por depósitos fluviais entrelaçados, dando início ao trato de sistema de alta taxa de acomodação (formações Uberaba e Marília). Nessa fase, os fluxos fluviais apresentavam-se perenes sob a forma de grandes lençóis arenosos em uma planície entrelaçada, recortados por canais menores com baixa sinuosidade (elementos DA, SB e LS). A estabilização do nível de base estratigráfico ocorreu com o aumento do espaço de acomodação subaéreo culminando com a acumulação de depósitos aluviais proximais. O predomínio de ele- mentos $\mathrm{CH}$, GB e SG (canais menores e formas de leito cascalhentas) marcam o trato de sistema de alta taxa de acomodação, cuja causa está relacionada à tectônica de soerguimento das bordas norte e nordeste da Bacia Bauru. Variações ocorridas na evolução fluvial em função das variações do nível de base são discutidas por Schumm (1993).

A configuração em área desses depósitos sugere um grande sistema de leques aluviais dominados por rios entrelaçados, gerados a partir fluxos gravitacionais e laminares que adentravam a bacia de nordeste para sudoeste, oriundos principalmente do Soerguimento do Alto Paranaíba e Província Alcalina de Goiás, em direção a um nível de base lacustre, conforme proposto por Batezelli (2003).

O bloco diagrama da figura 16 ilustra, de forma esquemática, a evolução do sistema aluvial da Bacia Bauru, durante o Cretáceo Superior.

CONCLUSÕES A reconstrução paleoambiental da porção norte e nordeste da Bacia Bauru através da análise de fácies, elementos arquitetônicos e paleocorrentes, indica que os depósitos do Grupo Bauru foram 


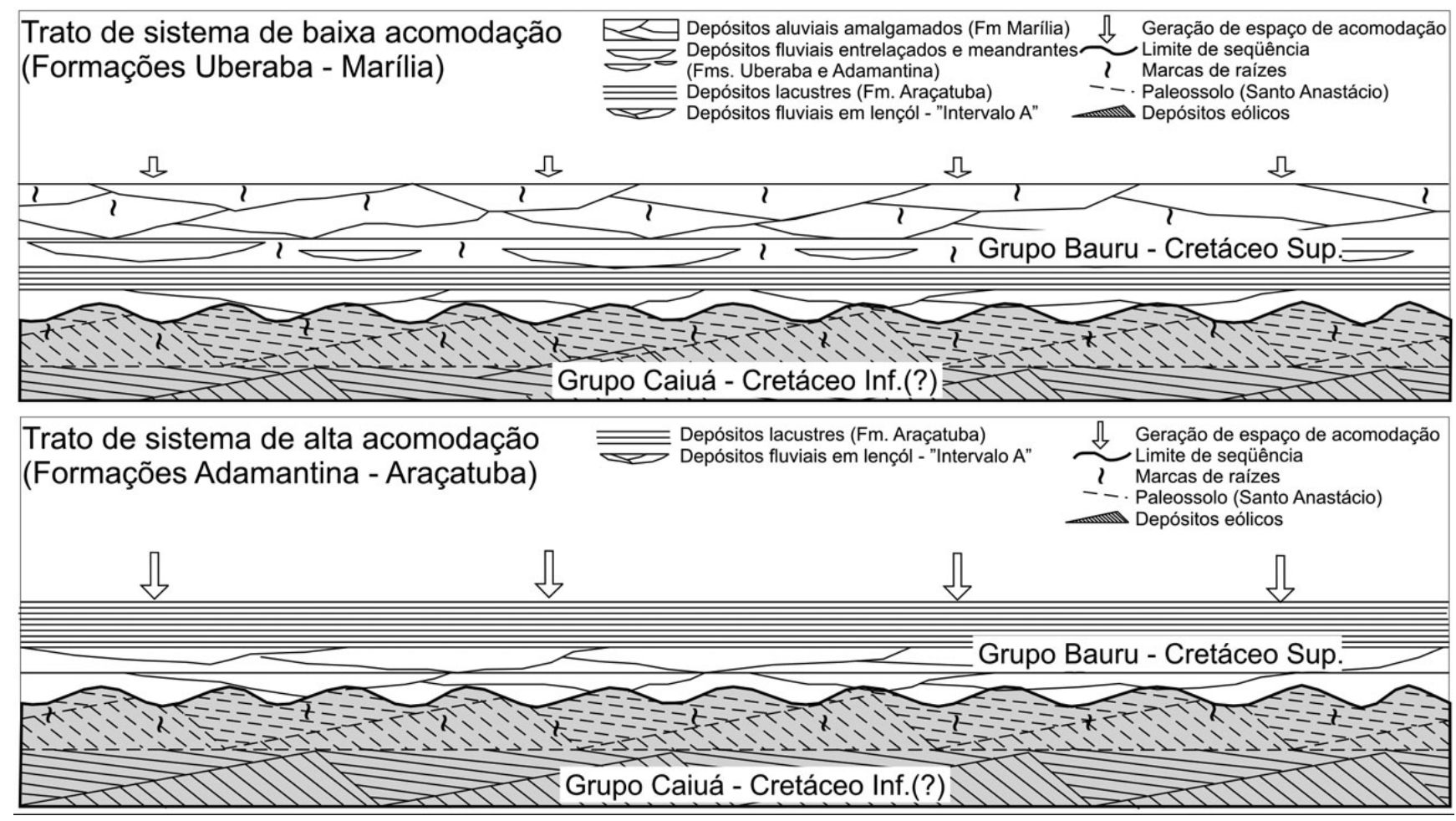

Figura 15 - Arquitetura aluvial da seqüência neocretácea da Bacia Bauru.

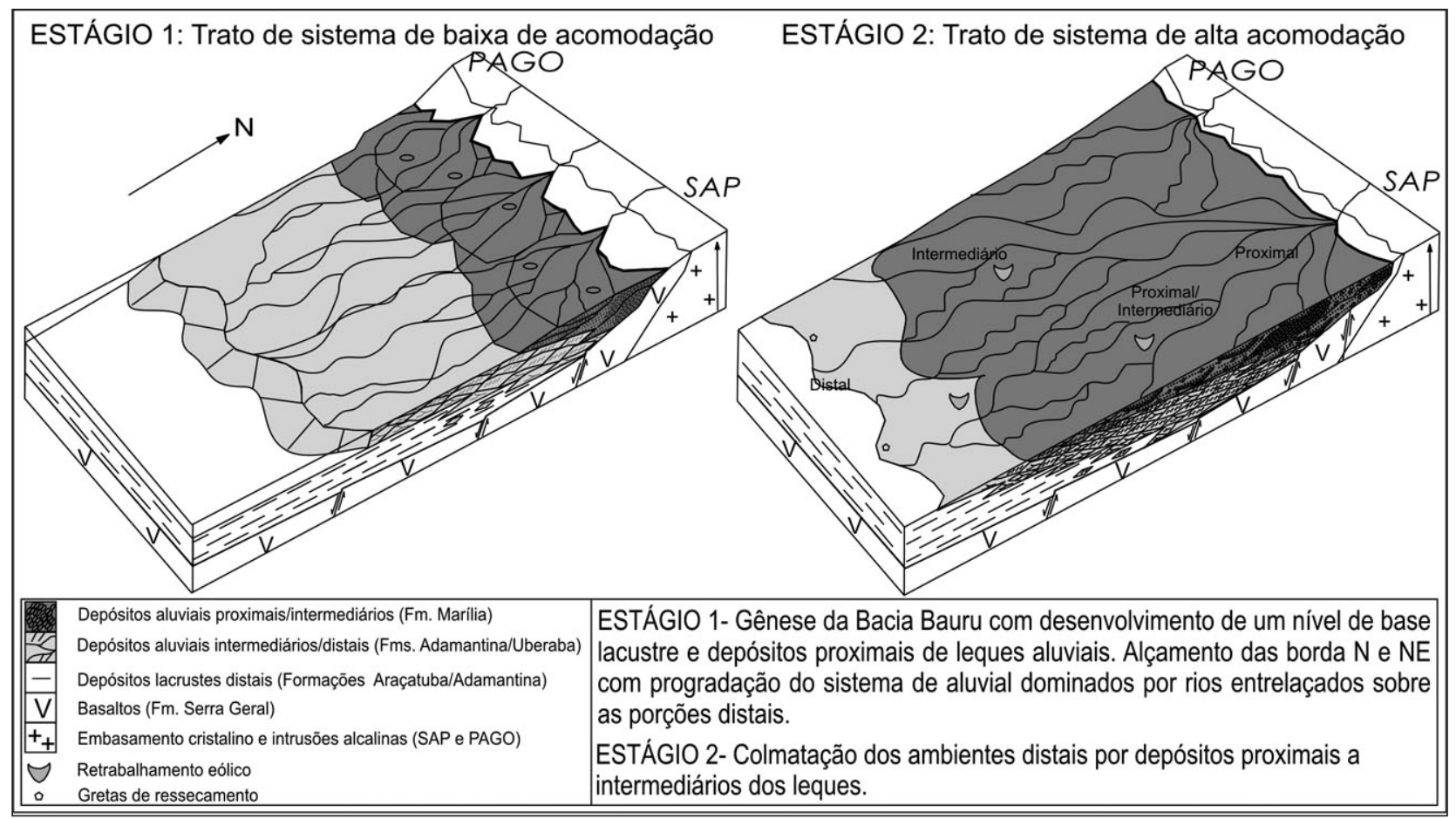

Figura 16 - Modelo esquemático de evolução da seqüência continental neocretácea da porção norte e nordeste da Bacia Bauru (Batezelli, 2003 - Mod.).

formados a partir de fluxos unidirecionais e gravitacionais de alta energia, associados a porções proximais e intermediárias de leques aluviais advindos de norte e nordeste.

Fácies conglomeráticas e arenosas (Cea, $\mathrm{Cmm}$, Cet, Aea, Aet, Alp, Am) associadas às macroformas de acréscimo à jusante (elemento DA), barras arenosas (elementos SB), barras cascalhentas (elementos SG), canais menores (elementos $\mathrm{CH}$ ), e subordinadamente, macroformas de acréscimo lateral (elementos LA) indicam que a fase de sedimentação aluvial foi marcada por rios do tipo entrelaçado, com baixa sinuosidade, 
que corriam de norte e nordeste para sul e sudoeste, advindos de Soerguimento do Alto Paranaíba (SAP) e da Província Alcalina de Goiás (PAGO).

Embora não tenham sido encontradas superfícies de $6^{\mathrm{a}}$ a $8^{\mathrm{a}}$ ordens (Miall, 1996), que definem precisamente as seqüências estratigráficas continentais, foi possível elaborar um modelo de evolução para seqüência neocretácea baseado na variação dos estilos deposicionais em função do aporte sedimentar. A arquitetura deposicional do Grupo Bauru definida por depósitos finos na base (formações Araçatuba e Adamantina), sobreposta por depósitos aluviais no topo (formações Uberaba e Marília) indica diminuição na razão entre taxa de acomodação e suprimento sedimentar, registrando dois tratos de sistemas: trato de sistema de alta taxa de acomodação e trato de sistema de baixa taxa de acomodação.
Estudo detalhados sobre os paleosolos identificados no Grupo Bauru fornecerão importantes subsídios para definição de limites de seqüências na Bacia Bauru. A caracterização micromorfológica desses paleosolos poderão revelar com maior exatidão quais processos atuaram na evolução da bacia, sua relação com as variações do nível do freático, espaço de acomodação subaéreo, além do reconhecimento de interflúvios que correspondam a superfícies limítrofes mais detalhadas.

Agradecimentos A Fundação de Amparo à Pesquisa do Estado de São Paulo - FAPESP pelo apoio financeiro ao projeto 04/13387-1. Ao Professor Dr. Vicente José Fulfaro e aos consultores e relatores da Revista Brasileira de Geociências pelas críticas e sugestões conferidas ao artigo.

\section{Referências}

Allen J.R.L. 1974. Studies in fluviatile sedimentation: implications of pedogenic carbonate units, Lower Old Red Sandstone. Anglo-Welsh outcrop. Geol. J., 9:181208.

Batezelli A. 2003. Análise da Sedimentação Cretácea no Triângulo Mineiro e sua Correlação com Áreas Adjacentes.Tese de Doutoramento, Inst. Geociências e Ciências Exatas, Universidade Estadual Paulista, 183 p.

BatezelliA., Gomes N. S., Perinotto J.A. de J. 2005. Petrografia e Evolução Diagenética dos Arenitos da Porção Norte e Nordeste da Bacia Bauru (Cretáceo Superior). Revista Brasileira de Geociências, 35(3):311-322.

Batezelli A., Saad A.R., Etchebehere M.L. de C., Perinotto J.A. de J., Fulfaro V. J. 2003. Análise Estratigráfica Aplicada À Formação Araçatuba (Grupo Bauru - Ks) no Centro-Oeste do Estado de São Paulo. Geociências, 22:05-19 (ed. Especial).

Bridge J. S. 1993. Description and Interpretation of Fluvial Deposits: a Critical Perspective. Sedimentology, 40(4):801-810.

Bromley M. H. 1991. Variation in Fluvial Style as revealed by Architecture Elements, Kayenta Formation, Mesa Creek, Colorado, USA: Evidence or Both Ephemeral and perennial Fluvial Processes. In: A. D. Miall \& N. Tyler (eds.) The Three-Dimensional Facies Architecture of Terrigenous Clastics Sediments and Its Implications For Hydrocarbon Discovery and Recovery. Concepts in Sedimentology and Paleontology. Oklahoma, USA, SEPM, v. 3, Tulsa p. 94-102.

Cowan E.J. 1991. The Large-scale architecture of fluvial Westwater Canyon Member, Morrison Formation (Jurassic), San Juan Basin, New Mexico. In: A.D. Miall \& N. (eds.)Tyler The Three-Dimensional Facies Architecture of Terrigenous Clastics Sediments and Its Implications For Hydrocarbon Discovery and Recovery. Concepts in Sedimentology and Paleontology. Oklahoma, USA. SEPM, v. 3, Tulsa, 309p.

Currie B.S. 1997. Sequence Stratigraphy of Nonmarine Jurassic-Cretaceous Rocks, Central Cordilleran Forelandbasin System. Geol. Soc. of Am. Bull., 109:1206-1222.
Decelles P.G., Gray M.B., Ridgway K.D., Cole R.B., Pivnik D.A., Pequera N., Srivastava P. 1991. Controls on Synorogenic Alluvial-fan Architecture, Beartooth Conglomerate (Paleocene), Wyoming and Montana. Sedimentology, 38(4):567-590.

Fernandes L.A., Coimbra A.M. 2000. Revisão Estratigráfica da Parte Oriental da Bacia Bauru (Neocretáceo). Revista Brasileira de Geociências, 30(4):717-728.

Ferreira Jr. P.D. 1996. Modelo Deposicional e Evolução Diagenética da Formação Uberaba, Cretáceo Superior da Bacia do Paraná, na Região do Triângulo Mineiro. Ouro Preto, Dissertação de Mestrado, Universidade Federal de Ouro Preto, 175p.

Ferreira Jr. P.D. \& Guerra W.J. 1995. Análise de Elementos Arquiteturais na Caracterização do Sistema Fluvial da Formação Uberaba, Cretáceo Superior da Bacia do Paraná no Triângulo Mineiro. In: SBG/MG, Simp. Geol. de M. Gerais, 8, Diamantina, Anais, v. 13, p. 104-106.

Galloway W. E. \& Hobday D. K. 1983. Terrigenous Clastic Depositional Systems - Applications to Petroleum, Coal and Uranium Exploration. N. York, S.Verlag, 423 p.

Hasui Y., Haralyi N.L E., Miotto J.A., Saad A.R., Campanha V.A., Hanza V.M., Frangipani A., Puleghini F.P. 1989. Compartimentação Estrutural e Evolução Tectônica do Estado S. Paulo. São Paulo, 2v. IPT, (Relatório 27.394).

Hirst J.P.P. 1991. Variations in Alluvial Architecture Across The Oligo-Mioceno Huesca Fluvial System Ebro Basin, Spain In: A.D. Miall \& N. Tyler (eds.) The ThreeDimensional Facies Architecture of Terrigenous Clastics Sediments and Its Implications For Hydrocarbon Discovery and Recovery. Concepts in Sedimentology and Paleontology. SEPM, v. 3, Oklahoma, USA, Tulsa, p. 111-121.

Jones S.J., Frostick L.E., Astin T.R. 2001. Braided Stream and Flood Plain Architecture: The Rio Vero Formation, Spanish Pyrenees. Sedimentary Geology, 139:229-260.

King C.L. 1956. A Geomorfologia do Brasil Oriental. Revista Brasileira de Geografia, 18(2):147-256.

Komatsubara J. 2004. Fluvial architecture and sequence stratigraphy of the Eocene to Oligocene Iwaki Formation, 
northeast Japan: channel-fill related to sea-leval change. Sedimentary Geology, 168:109-123.

Krumbein W.C. \& Sloss L.L. 1963. Stratigraphy and Sedimentation. 2nd ed., San Francisco, Freeman, 660 p.

Lima C.C.U. de \& Villas-Boas G.S. 2000. A Arquitetura Deposicional da Formação Marizal (Cretáceo Inferior) na Bacia do Recôncavo, Bahia. Revista Brasileira de Geociências, 30(4):729-736.

Martinsen O.J., Ryseth A., Helland-Hansen W., Fleshe H., Torkildsen G., Idill S. 1999. Stratigraphic Base Level and Fluvial Architecture: Ericson Sandstone (Campanian), Rocky Springs Uplift, Sw Wyoming, USA. Sedimentology, 46:235-259.

McCarthy P.J. \& Plint A.J. 1998. Recognition of interfluve sequence boundaries: integrating paleopedology and sequence stratigraphy. Geology, 26:387-390.

McCarthy P.J., Faccini U.F., Plint A.J. 1999. Evolution of an ancient floodplain: paleosols and alluvial architecture in a sequence stratigraphic framework, Cenomanian Dunvegan Formation, NE British Columbia, Canada. Sedimentology, 46:861-891.

Miall A.D. 1978. Lithofacies Types and Vertical Profile Models in Braided River Deposits: a summary. In: A.D. Miall (ed.) Fluvial Sedimentology. Can. Soc. Petrol. Geol. Mem., v. 5, p. 597-604.

Miall A.D. 1984. Principles of Sedimentary Basin Analysis. New York Inc., Springer-Verlag, 490p.

Miall A.D. 1985. Architectural-Element Analysis: A New Method of Facies Analysis Applied to Fluvial Deposits. Earth Science Reviews, 22(4):261-300.

Miall A.D. 1988a. Reservoir Heterogeneities in Fluvial Sandstones: Lessons from Outcrop Studies. American Assoc. of Petroleum Geologists Bulletin, 72(6):682-697.

Miall A.D. 1988b. Architectural Elements and Bouding Surfaces In Fluvial Deposits: Anatomy of the Kayenta Formation (Lower Jurassic) Southwest Colorado. Sedimentary Geology, 55(2):233-262.

Miall A.D. 1994. Reconstructing Fluvial Macroform Architecture from Two-dimensional Outcrops: Examples from the Castlegate Sandstone, Bookc Cliffs, Utah. Jounal of Sedimentary Research, B64(2):146-158.

Miall A.D. 1996. The Geology of Fluvial Deposits. Berlin, Springer-Verlag, 582p.

Miall A.D. \& Turner-Peterson C.E. 1989. Variations in fluvial style in the Westwater Canyon Member, Morrison Formation (Jurassic), San Juan Basin, Colorado Plateau. Sedimentary Geology, 63:21-60.

Miall A.D. \& Jones B.G. 2003. Fluvial architecture of the Hawkesbury Sandstone (Triassic), near Sydney, Australia. Jl.of Sedimentary Research, 73(4):531-545.

Miall A.D. \& Tyler N. 1991. The Three-Dimensional Facies Architecture of Terrigenous Clastics Sediments and Its Implications for Hydrocarbon Discovery and Recovery. Concepts in Sedimentology and Paleontology. Oklahoma, USA, SEPM, v. 3, Tulsa, 309p.

Moore R.C. 1949. Meaning of Facies. Geol. Soc. Am. Mem., 39:1-34.

Plint A.J., McCarthy P.J., Faccini U.F. 2001. Nonmarine sequencestratigraphy: updip expression of sequence boundaries and systems tracts in a high resolution framework, Cenomanian Dunvegan Formation, Alberta Foreland Basin, Canadá. American Association of Petroleum Geology Bulletin, 85(11):1967-2001.

Posamentier H.W. \& Allen G. P. 1993a. Siliciclastic sequence stratigraphic pattern in foreland ramp-type basins. Geology, 21:455-458.

Posamentier H.W. \& Allen G. P 1993b. Variability of sequence-stratigraphic models: effects of local basin factors. Sedimentary Geology, 86:91-109.

Posamentier H.W., Jervey M.T., Vail P.R. 1988. Eustatic control on clastic depositional - Conceptual framework. In: K.C. Wilgus, C.A Ross, H. Posamentier (eds.) Sealevel Changes: an Integrated Approach. Tulsa, SEPM, p. 109-124. (SEPM Special Publ, 42).

Ramos A. \& Sopeña A. 1983. Gravel Bars in Low-Sinuosity Streams (Permian and Triassic, Central Spain). In: J.D. Collinson \& J. Lewis (eds). Modern and Ancient Fluvial Systems. Int. As. Sediment. Spec.Publ. v.6, p.301-312.

Reading H. G. 1996. Sedimentary Environments: Processes, Facies and Stratigraphy. $3^{\text {th }}$ Edition, USA, Blackwell Science, 688p.

Schumm S.A. 1993. River response to base level change: implications for sequence stratigraphy. Journal of Geology, 101:279-294.

Shanley K.W. \& McCabe P.J. 1991. Predicting facies architecture through sequence stratigraphy - an example from the Kaiparowitz Plateau, Utah. Geology, 19:742745.

Shanley K.W. \& McCabe P.J. 1993. Alluvial architecture in a sequence stratigraphic framework: a case history from the Upper Cretaceous of southern Utah, USA. In: S.S. Flint \& I.D. Byant (eds.) The Geological Modeling of Hydrocarbon Reservoir and Outcrop Analogues. Oxford, IAS, p. 21-56. (IAS Spec. Publ. \# 15).

Shanley K.W. \& McCabe P.J. 1994. Perspectives on sequence stratigraphy of continental strata. Am. American Assoc. of Petroleum Geology Bulletin, 78(4):544-568.

Smith S.A. 1990. The Sedimentology and Accretionary Style of an Ancient Gravel-bed Stream: The Budleigh Salterton Pebble Beds (Lower Triassic), Southwest England. Sedimentary Geology, 67:199-219.

Stanistreet I.G. \& McCarthy T.S. 1993. The Okavango Fan and the classification of sub aerial fan systems. Sedimentary Geology, 85:115-133.

Teichert C. 1958. Concept of Facies. American Association of Petroleum Geology Bulletin, 42:2718-2744.

Van Wagoner J.C.; Mittchum R.M., Campion K.M.; Rahmanian V.D. 1990. Siliciclastic sequence stratigraphy in well logs, cores, and outcrops. American Assoc.of Petroleum Geology Methods Explorer, 62(7):932-966.

Walker R.G. 1984. Facies model. 2 ed., Canada, Geosciences, Reprint Series 1, 317 p.

Manuscrito A-1650 Aceito em 02 de maio de 2007 